Final Technical Report

\title{
A Comparative Study of Welded ODS Cladding Materials for AFCI/GNEP Applications
}

(DOE Grant \# DE-FG07-08ID14925)

Project Director: Indrajit Charit
University of Idaho

Submitted on March 31, 2011 


\section{Project-Specific Details}

Project Title: A Comparative Study of Welded ODS Cladding Materials for AFCI/GNEP Applications

Report Type: Final report (incorporating last quarterly report)

DOE Grant \# DE-FG07-08ID14925

Project Start Date: Oct. 1, 2008; Project End date: Dec. 31, 2010

Principal Investigator (PI) / Project Director (PD):

Indrajit Charit, Assistant Professor

Materials Science and Engineering \& Nuclear Engineering Programs

University of Idaho, Moscow, ID 83844-3024

Phone: 208-885-5964, Fax: 208-885-0154, E-mail: icharit@uidaho.edu

Other PIs and Participating Institutions:

Megan Frary, Darryl Butt (Boise State University)

K.L. Murty (North Carolina State University)

Larry Zirker, James Cole and Mitchell Meyer (Idaho National Laboratory)

Rajiv S. Mishra (Missouri University of Science and Technology), up to Sep. 30, 2009

Mark Woltz (Centerline Limited) 


\section{PROJECT ABSTRACT}

This research project involved working on the pressure resistance welding of oxide dispersion strengthened (ODS) alloys which will have a large role to play in advanced nuclear reactors. The project also demonstrated the research collaboration between four universities and one national laboratory (Idaho National Laboratory) with participation from an industry for developing for ODS alloys. These alloys contain a high number density of very fine oxide particles that can impart high temperature strength and radiation damage resistance suitable for in-core applications in advanced reactors. The conventional fusion welding techniques tend to produce porosity-laden microstructure in the weld region and lead to the agglomeration and non-uniform distribution of the needed oxide particles. That is why two solid state welding methods pressure resistance welding (PRW) and friction stir welding (FSW) - were chosen to be evaluated in this project. The proposal is expected to support the development of Advanced Burner Reactors (ABR) under the GNEP program (now incorporated in Fuel Cycle R\&D program). The outcomes of the concluded research include training of graduate and undergraduate students and get them interested in nuclear related research. The primary research components of the proposal were the following:

PRW and FSW were applied to two mechanically alloyed (MA) ODS alloys. The process optimization was carried out to get to a process window that worked for the alloys.

Microstructures and mechanical properties of the as received and welded materials were characterized using a number of advanced characterization tools (SEM/EDS/EBSD and TEM). Mechanical properties were evaluated using microhardness, tensile testing, crack growth tests under fatigue loading and burst testing.

The as received and friction stir welded alloys were irradiated in the Advanced Test Reactor (ATR). The samples are still being evaluated due to some schedule delay.

Overall, the project highlighted that the use of solid state welding techniques can open up new opportunities in nuclear reactor applications, and the high performance alloys like ODS alloys would require these techniques in order to retain their best properties. These welding techniques can be developed as an 'enabling technology' in nuclear applications. 


\section{A. INTRODUCTION}

The project has supported the goals of the Advanced Fuel Cycle Initiative and Global Nuclear Energy Partnership (presently known as Fuel Cycle R\&D) of the Department of Energy. The project aimed to facilitate the development of advanced structural/cladding materials (core internal materials) for the Advanced Burner Reactor (ABR) [Cahalan, 2007]. Improved economics and reliability are important features of any reactor. High performance materials will help in allowing higher temperatures, longer life times and reduced down-time of reactors. Superior performance of structural materials for in-core applications will improve flexibility in the design and operation of reactors that need to operate at higher temperatures for longer times and receiving higher radiation damage. Materials employed should have the adequate properties in order to offer better performance and economics. In recent years, oxide dispersion strengthened (ODS) alloys have attracted much interest for their good elevated temperature properties and radiation damage resistance [Klueh et al., 2005]. This has particularly important implications for cladding materials which are integrated into the fuel programs. It has been noted that the ODS alloys possess excellent creep resistance combined with high radiation damage tolerance (swelling and embrittlement) due to the presence of finely dispersed (typically $<15 \mathrm{~nm}$ in diameter) oxide particles. However, for fabricating large in-core reactor structures with design complexity, joining of components is essential. Conventional fusion welding techniques applied to the ODS alloys pose serious challenges as they produce undesirable microstructures. For example, these may lead to excessive level of porosity, and the agglomeration of fine oxide particles into much coarser ones [Seki et al., 2004]. Hence, it is important to examine the possibilities of applying welding techniques, such as pressure resistance welding (PRW) and friction stir welding (FSW) that do not have the drawbacks like those encountered in conventional fusion welding techniques, and whether they would retain as excellent properties in the welded joints as they do in monolithic forms. The aim of the project was to investigate the characteristics of welded joints (pressure resistance welding and friction stir welding) of two ODS alloys; a ferritic steel MA 956 (Fe- 18.5-21.5Cr 3.75-5.75Al 03.-0.7 $\mathrm{Y}_{2} \mathrm{O}_{3}$, wt.\%) and nickel-base superalloy MA 754 (Ni- 20Cr-0.3Al-0.5Ti-1Fe-0.05C-0.6 $\mathrm{Y}_{2} \mathrm{O}_{3}$, wt.\%) under unirradiated and irradiated conditions. The research focused on first generation (formerly) commercial alloys MA956 and MA754 as prototype materials due to the available supply.

The following objectives have been addressed in the concluded project:

1) Process development of pressure resistance welding (PRW) and friction stir welding (FSW) techniques with regards to joining ODS alloys for fuel cladding applications.

2) Study the microstructure, microtexture and mechanical properties (tensile, creep, weld crack growth experiments, and automated ball indentation tests) of the welded materials.

3) Study of the effect of fast neutron radiation exposure and perform appropriate postirradiation examination (tensile testing, shear punch testing).

4) Development of appropriate structure-property correlations in the chosen ODS alloys. 
5) Support directly the ongoing research activities at INL in the AFCI/GNEP (Fuel Cycle R\&D) program.

\section{B. TECHNICAL BACKGROUND}

\section{B1. GNEP and ABR}

GNEP as a part of the Advanced Energy Initiative of 2005 aimed at expanding the use of nuclear energy throughout the globe (Note that GNEP program has been discontinued). One of the specific goals was to develop fuel cycles that could take care of radioactive wastes and encourage non-proliferation while promoting nuclear security. If successful, this will revolutionize the way the radioactive wastes are dealt with in the United States and abroad. ABR was a key component of the GNEP strategy. ABR would run on the transmutation engineered spent fuel forms and burn down the harmful transuranic elements from the spent radioactive fuel (e.g. plutonium, americium, neptunium etc.) through transmutation reactions while co-producing electricity. ABR would closely resemble a sodium fast reactor but will have improved design and safety features. Thermal reactors are only of limited help in the transmutation of actinides, and with them the problem of proliferation (the separation of plutonium) remains. Fast reactors such as the envisioned ABR would effectively burn down the transuranics.

\section{B2. Cladding Materials for ABR}

ABR will involve transmutation of transuranic (TRU) fuel forms that must be encapsulated in high performance fuel pin cladding materials. A number of attributes determine the best fit candidate material for advanced reactors [Busby, 2007]:

a) Improved mechanical properties (strength, ductility, toughness, creep properties etc.)

b) Improved thermal properties (thermal conductivity, thermal expansion coefficient)

c) Resistance to environments (coolant and irradiation)

d) Availability and cost

e) Neutronics

f) Cost (raw materials, joining and quality assurance costs)

g) Joining and fabrication

General ferritic/martensitic steels may not be suitable for applications in GNEP concept reactors. Appreciable radiation hardening and embrittlement at temperatures of $\sim 400{ }^{\circ} \mathrm{C}$ or less is a problem as also the poor strength properties at higher temperatures and chemical compatibility issues [Klueh, 2005]. The development of dispersion strengthened alloys by internal oxidation and the invention of dispersion-strengthened aluminum (Sintered Aluminum Powder or SAP) led to a widespread interest in using this mode of strengthening in other alloy systems. Although TD-Ni and TD-Ni-Cr alloys were developed through conventional powder metallurgy techniques, the technical breakthrough in this area came from Benjamin via the mechanical alloying technique using high energy ball milling [Benjamin, 1970]. Several commercial 
mechanically alloyed Ni-base superalloys (such as MA754, MA758, MA6000), various MAODS steels (such as MA956, MA957) and other ODS alloys have been developed over the years. In recent years, ODS steels have shown much promise for their possible use in much harsher environment of nuclear reactors where materials performance is a critical factor [Kimura, 2006]. Recent research on nanostructured ferritic steels revealed outstanding creep resistance at high temperatures [Kim et al., 2003; Hoelzer et al., 2007]. It is more the presence of nanoclusters arising in the processing rather than oxide particles initially present at several times the size of the nanoclusters, which impart superior properties to these alloys.

In this study, we plan to work on two important ODS alloys - MA956 and MA754 alloys, both incorporating fine yttrium oxide $\left(\mathrm{Y}_{2} \mathrm{O}_{3}\right)$ particles. Several studies have focused on aspects of processing, microstructure and properties of monolithic alloys. However, from a systems perspective, evaluation of right welding technique is of overriding importance. Any welding technique would change the microstructure at the weld joint and consequently change the properties. Hence, properties with which we start with will not be the same after welding. That is why it is very important to choose the right technique and follow appropriate weld qualification procedures.

\section{B3. Welding Techniques}

It has been known for some time that conventional fusion welding techniques tend to produce a higher level of porosity and cast microstructure leading to poor properties. One such example from a gas tungsten arc welded (GTAWed) MA957 alloy is shown in Figure 1. The strongest fusion-welded joints for ODS alloys are produced by the application of laser-beam welding and electron-beam welding. Therefore, solid state joining techniques are a way to improve the weld quality of the ODS alloys and have real implications for their use in the advanced reactors. In the concluded project, we chose two promising welding techniques, PRW and FSW, for this purpose.

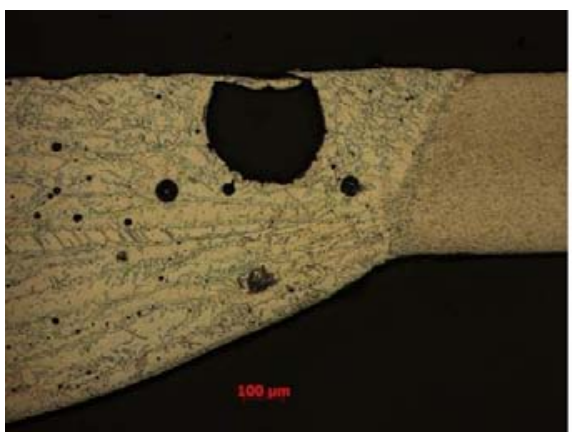

a) $100 X$

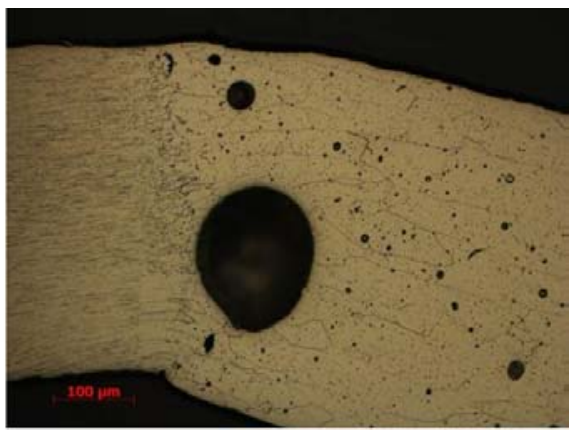

b) $500 \mathrm{X}$

Figure 1. Application of GTAW to a MA957 cladding tube.

$\boldsymbol{P R} \boldsymbol{W}$. PRW utilizes the heat generated by the electrical resistance at the butt-aligned joint interface of welding materials under a specific axial pressure while passing a large current density and hence higher temperature at the contact area compared to other areas [Seki et al., 
2004; Zirker et al., 1991; Bottcher et al., 2002]. Also, the specific resistance heating increases as the temperature increases, thus allowing increase of temperature at the contact area drastically. The interface contact area between the end plug and the tube rapidly softened by $\mathrm{I}^{2} \mathrm{R}$ heating and is expelled by the force of the PRW process. The expulsion causes a burr or weld upset formed in the solid state reducing the heat affected zone. The welding parameters include welding current (amps), welding time (cycles) and the electrode force. Prior to the project efforts, the solid state PRW technique has been studied in ODS alloys to a limited extent (Fig. 2a), but exhibited good results. A detailed study of PRW technique on ODS alloys was essential to fully assess its utilization and evaluate the weldability of the materials for advanced reactor use.

FSW. FSW has been developed as a highly efficient, versatile and environmentally benign solid state joining technique [Thomas et al., 1991]. This technique uses a high strength, nonconsumable rotating tool that creates heat due to the friction between the tool shoulder (Fig. 2b) and adiabatic heating. The heat softens the material which is moved from front to the back of the tool, and a joint is created. FSW is a unique solid state joining technique developed initially for aluminum alloys for mainly aerospace and automotive applications. It has several interesting features: a) No filler material or fluxes are required, and no harmful gas is produced during the welding process, b) less amount of heat, c) less residual stress and distortion, d) improved joint efficiency with fine, dynamically recrystallized grain structure at the joint, and e) ability to join dissimilar materials. FSW leads to a fine grained microstructure due to a dynamic recrystallization process. Recently, FSW has been applied to an ODS steel (MA 957 alloy) [Feng and Weijun, 2007]. However, no detailed microstructural characterization of the stir (nugget) zone was made and mechanical performance data are not known. Alloy composition and FSW parameters (such as, tool rotation rate, tool traverse speed and tool geometry) influence the microstructural development. Hence, it is essential to understand the complex interactions that FSW induces during severe plastic deformation, and its impact on the properties of the welded zone as compared to the base material.
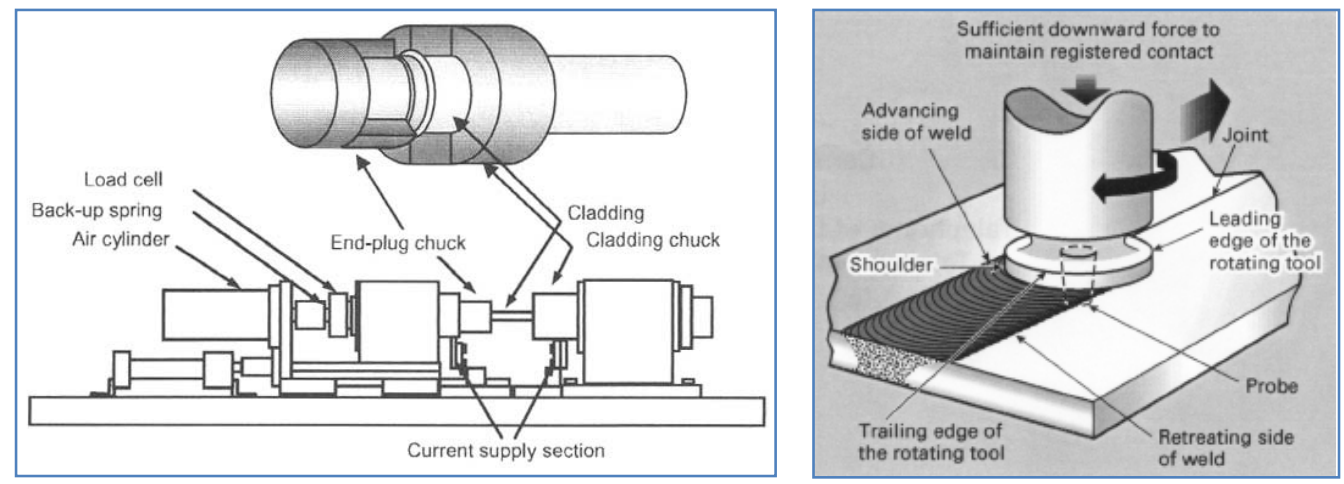

Figure 2. a) A schematic of PRW technique as applied to cladding material [Seki et al., 2004]. b) A schematic of FSW process [Thomas et al., 1991]. 


\section{RESULTS \& DISCUSSION}

\section{C1. Friction Stir Welding}

\section{C1.1 MA754 Alloy}

A 12\%WC-Co cermet tool with $1 \mathrm{~mm}$ pin diameter/height and $10 \mathrm{~mm}$ shoulder was used. After trial and error runs, various combinations of parameters were used for friction stir welding both alloys; tool rotation rate of $1000 \mathrm{rpm}$, a traverse speed of $2 \mathrm{ipm}$, and tool plunge depth of about $1.25 \mathrm{~mm}$ were found optimum. The tool was slanted at an angle of $3^{\circ}$ to the surface of the plate. The FSW runs were made as a bead-on-plate configuration, i.e. FSW was carried out on a monolithic plate in place of joining two separate plates. A view of the two FSW runs made on the MA754 alloy is shown in Fig. 3a. A thermal profile of one FSW run is shown in Fig. 3b, showing temperatures at two particular locations in MA956 alloy during friction stir welding.

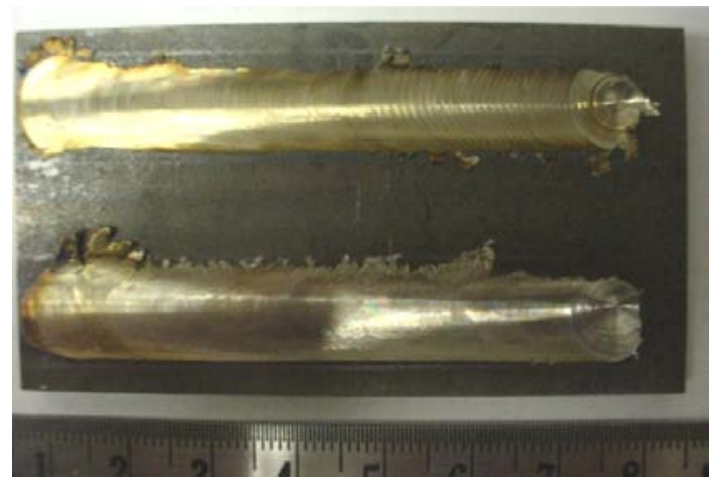

(a)

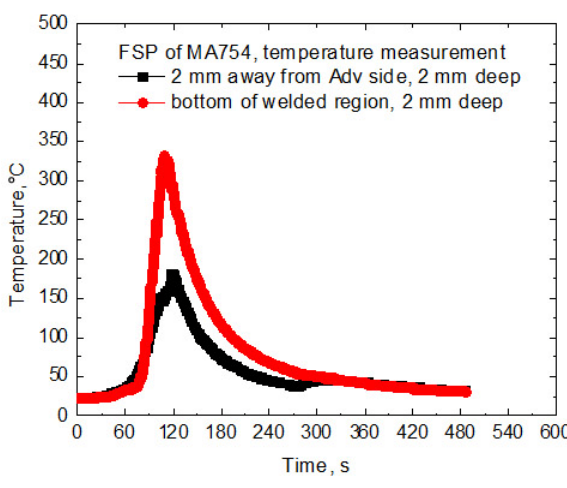

(b)

Figure 3. a) A view of the friction stir welds of MA754 alloy plate (bead-on-plate configuration). b) Thermal profile at certain locations on the friction stir weld of MA754 alloy (thermocouples were placed at $2 \mathrm{~mm}$ away from the advancing side at $2 \mathrm{~mm}$ deep, and $2 \mathrm{~mm}$ from the bottom of the welded region again at $2 \mathrm{~mm}$ deep). Note that the actual stir zone temperature is higher than what is shown in the temperature profile.

Fig. 4(a) shows the macrostructure of the transverse cross-section of a typical FSW MA754 sample. The stir zone (weld nugget) is approximately in the center (shown as the light colored region in the figure). Fig. 4(b) shows the microstructure of the base material side of the weld zone. They were received in a hot rolled condition and had significantly larger grain size. For example, Fig. 1 shows the nugget zone microstructures developed using 16CY-2 tool with the tool rotation rate of $800 \mathrm{rpm}$ and traverse speed of $2 \mathrm{ipm}$. The grain structure was so fine that it could not be resolved well using optical microscopy. Figure 5 shows the effect of different tools on the grain size in the stir zone. 


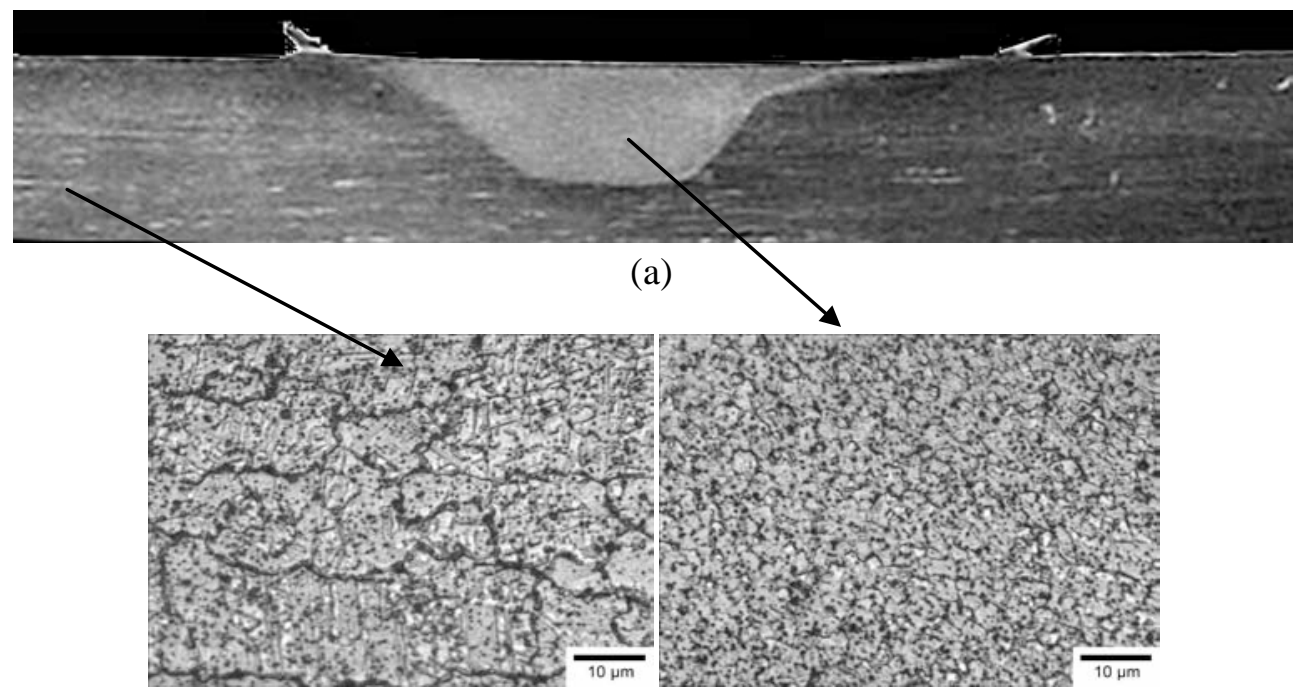

(b)

(c)

Figure 4. An optical macrograph of the transverse cross-section of FSW MA754 alloy. Also shown are the optical micrographs of the base material and the stir zone as revealed by the optical microscopy.

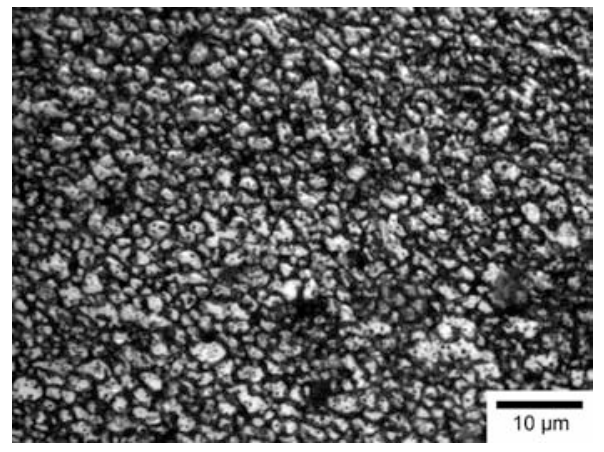

(a)

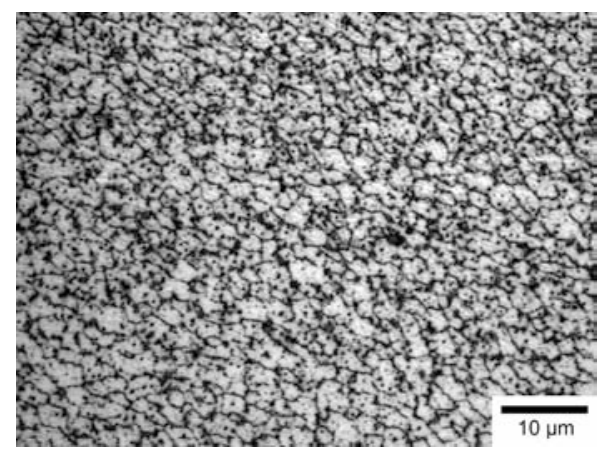

(b)

Figure 5. Optical micrographs of the nugget zone in the MA754 alloy welded using (a) CY16-2 tool and (b) CY16-1 tools using a tool rotation rate of $1000 \mathrm{rpm}$ and a traverse speed of $2 \mathrm{ipm}$.

\section{Mechanical Properties}

Microhardness (Vickers) profiles across the transverse cross-section of the welded zones of the three friction stir welds mentioned in the above section are shown in Figure 6a-c. There does not appear to be much variation between the nugget zone, heat affected zone and the base material region. 

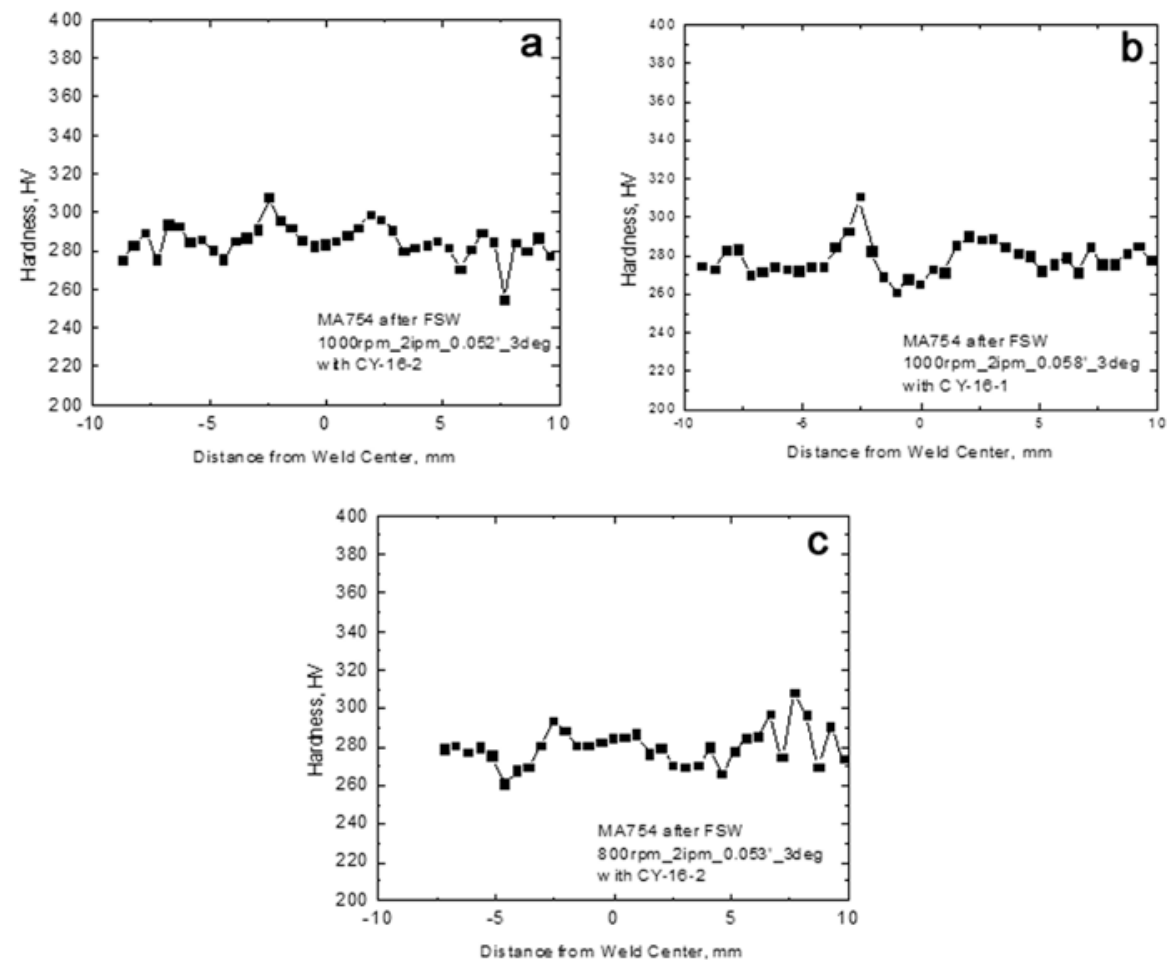

Figure 6. Microhardness profiles in transverse cross-section of the FSW alloys welded using different tool conditions.

Mini-tensile specimens were machined from the friction stir welded regions. Table 1 summarizes the tensile results of MA754 alloys welded using CY16-2 tools but with different parameters (800/2 and 1000/2). There are very slight differences in the tensile properties, but not a major one to be attributed to any microstructural conditions.

Table 1. A summary of the tensile properties of the nugget zone of MA754 alloys

\begin{tabular}{|c|c|c|c|}
\hline $\begin{array}{c}\text { MA754 } \\
\text { CY16-2 Tool } \\
800 \mathrm{rpm} \text { / } 2 \text { ipm } \\
\text { (Tensile specimen } \\
\text { gauge oriented parallel } \\
\text { to the rolling direction } \\
\text { in base MA754 alloy) }\end{array}$ & $\begin{array}{l}\text { Y.S.: } 709 \pm 12 \mathrm{MPa} \\
\text { U.T.S.: } 930 \pm 20 \mathrm{MPa} \\
\text { \%Elongation: } 22.1 \pm 2.8\end{array}$ & $\begin{array}{c}\text { MA754 } \\
\text { CY16-2 Tool } \\
1000 \mathrm{rpm} / 2 \mathrm{ipm} \\
\text { (Tensile specimen gauge } \\
\text { oriented parallel to the } \\
\text { rolling direction in base } \\
\text { MA754 alloy) }\end{array}$ & $\begin{array}{l}\text { Y.S.: } 721 \pm 11 \mathrm{MPa} \\
\text { U.T.S.: } 955 \pm 6 \mathrm{MPa} \\
\text { \%Elongation: } 25.9 \pm 1.2\end{array}$ \\
\hline $\begin{array}{c}\text { MA754 } \\
\text { CY16-2 Tool } \\
800 \mathrm{rpm} / 2 \mathrm{ipm} \\
\text { (Tensile specimen gauge } \\
\text { oriented perpendicular to } \\
\text { the rolling direction in } \\
\text { base MA754 alloy) }\end{array}$ & $\begin{array}{c}\text { Y.S.: } 707 \pm 4 \mathrm{MPa} \\
\text { U.T.S.: } 947 \pm 8 \mathrm{MPa} \\
\text { \%Elongation:26.5 } \pm 2.9\end{array}$ & $\begin{array}{c}\text { MA754 } \\
\text { CY16-2 Tool } \\
1000 \mathrm{rpm} / 2 \mathrm{ipm} \\
\text { (Tensile specimen gauge } \\
\text { oriented perpendicular to } \\
\text { the rolling direction in } \\
\text { base MA754 alloy) }\end{array}$ & $\begin{array}{l}\text { Y.S.: } 706 \pm 27 \mathrm{MPa} \\
\text { U.T.S.: } 940 \pm 17 \mathrm{MPa} \\
\text { \%Elongation: } 19.3 \pm 4.0\end{array}$ \\
\hline
\end{tabular}


Out of these samples, MA754 alloy processed with a tool rotation rate of $1000 \mathrm{rpm}$ and a traverse speed of 2 ipm was chosen for further microstructural examination and mechanical properties evaluation.

The microstructure of MA754 alloy is shown in Fig. 5 (also shown in report 1). Base material microstructure is coarser than the fine grained nugget $(2-3 \mu \mathrm{m})$ microstructure. Table 2 summarizes the tensile properties of both base and stir zone materials. Mini tensile tests (gage length of the samples is $1 \mathrm{~mm}$ ) at room temperature have been carried out at a strain rate of $10^{-3}$ $\mathrm{s}^{-1}$ on the parent and stir zone samples. Room temperature properties of the base material and the stir zone are not very different with significant improvement in percentage elongation. At $538^{\circ} \mathrm{C}$, the stir zone material has good strength properties at $538{ }^{\circ} \mathrm{C}$ while the base material is just slightly better. It is interesting to note that the ductility falls off at higher temperature compared to the room temperature. The effect of strain rate on the strength is not conclusive, and does not show any clear trend.

Table 2. A summary of tensile properties of MA754 alloy

\begin{tabular}{|c|c|c|c|c|c|c|}
\hline \multirow{2}{*}{$\begin{array}{c}\text { Tensile Test } \\
\text { Conditions }\end{array}$} & \multicolumn{3}{|c|}{ Base Material MA754 } & \multicolumn{3}{c|}{ FSW Nugget MA754 } \\
\cline { 2 - 7 } $\begin{array}{c}\text { Temperature / } \\
\text { Strain Rate }\end{array}$ & Y.S. (MPa) & $\begin{array}{c}\text { U.T.S. } \\
\text { (MPa) }\end{array}$ & \%Elongation & Y.S. & U.T.S. & \%Elongation \\
(MPa) & (MPa) & \\
\hline $\mathbf{2 5}^{\mathbf{0}} \mathbf{C} / \mathbf{1 0}^{-3} \mathbf{s}^{-1}$ & $702 \pm 11$ & $1017 \pm 31$ & $18.7 \pm 1.5$ & $717 \pm 25$ & $969 \pm 9$ & $27.5 \pm 1.4$ \\
$\mathbf{5 3 8}^{\mathbf{C}} \mathbf{C} / \mathbf{1 0}^{-\mathbf{4}} \mathbf{s}^{-\mathbf{1}}$ & $625 \pm 25$ & $794 \pm 30$ & $11.6 \pm 2.2$ & $588 \pm 16$ & $794 \pm 49$ & $19.5 \pm 4.5$ \\
$\mathbf{5 3 8}^{\mathbf{0}} \mathbf{C} / \mathbf{1 0}^{-\mathbf{3}} \mathbf{s}^{-\mathbf{1}}$ & $666 \pm 43$ & $876 \pm 57$ & $14.8 \pm 1.3$ & $620 \pm 33$ & $837 \pm 23$ & $19.7 \pm 3.6$ \\
$\mathbf{5 3 8}^{\mathbf{0}} \mathbf{C} / \mathbf{1 0}^{-\mathbf{2}} \mathbf{s}^{-\mathbf{1}}$ & $662 \pm 51$ & $865 \pm 48$ & $16.0 \pm 0.8$ & $626 \pm 16$ & $847 \pm 15$ & $21.5 \pm 2.0$ \\
& & & & & & \\
\hline
\end{tabular}

\section{Thermal Stability Studies}

Some FSW samples of MA754 alloy were subjected to various heat-treatment cycles as listed in Table 3. The Mean Linear Intercept (MLI) and Spatial Grain Sizes of various zones were calculated to study the any possible grain growth studies. As a reference, heat-treatment of asreceived material was also carried out. The mean linear intercept (MLI) and spatial grain sizes of various zones are given in Table 8 reveal that no significant change was observed, which confirms the stability of the material at high temperature. Although the grain structure was changed when FSW was carried out, the oxide dispersion present might not have undergone much change after welding. 
Table 3. The Mean Linear Intercept (MLI) and Spatial Grain Sizes of FSW MA754

\begin{tabular}{|c|c|c|c|c|c|c|}
\hline \multirow[t]{2}{*}{ Condition } & \multicolumn{3}{|c|}{$\begin{array}{c}\text { Mean Linear Intercept (MLI) } \\
\text { Grain Size }(\mu \mathrm{m})\end{array}$} & \multicolumn{3}{|c|}{ 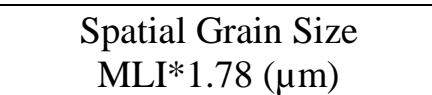 } \\
\hline & Top & Middle & Bottom & Top & Middle & Bottom \\
\hline \multicolumn{7}{|c|}{ Retreating Zone } \\
\hline $550,1 \mathrm{~h}$ & $1.7 \pm 0.1$ & $1.5 \pm 0.5$ & $1.3 \pm 0.1$ & $3.0 \pm 0.1$ & $2.6 \pm 0.5$ & $2.3 \pm 0.1$ \\
\hline $650,1 \mathrm{~h}$ & $1.7 \pm 0.3$ & $1.5 \pm 0.3$ & $1.2 \pm 0.8$ & $3.0 \pm 0.3$ & $2.6 \pm 0.5$ & $2.1 \pm 0.8$ \\
\hline $750,1 \mathrm{~h}$ & $1.7 \pm 0.3$ & $1.4 \pm 0.2$ & $1.2 \pm 0.3$ & $3.0 \pm 0.3$ & $2.4 \pm 0.2$ & $2.1 \pm 0.3$ \\
\hline $850,1 \mathrm{~h}$ & $1.6 \pm 0.5$ & $1.5 \pm 1.1$ & $1.2 \pm 0.2$ & $2.8 \pm 0.5$ & $2.6 \pm 1.1$ & $2.1 \pm 0.2$ \\
\hline $950,1 \mathrm{~h}$ & $1.7 \pm 0.8$ & $1.5 \pm 0.6$ & $1.3 \pm 0.8$ & $3.0 \pm 0.8$ & $2.6 \pm 0.6$ & $2.3 \pm 0.8$ \\
\hline $950,100 \mathrm{~h}$ & $1.8 \pm 0.7$ & $1.5 \pm 0.1$ & $1.3 \pm 0.7$ & $3.2 \pm 0.7$ & $2.6 \pm 0.1$ & $2.3 \pm 0.7$ \\
\hline $950,300 \mathrm{~h}$ & $1.8 \pm 1.1$ & $1.5 \pm 0.6$ & $1.3 \pm 0.5$ & $3.2 \pm 1.1$ & $2.6 \pm 0.6$ & $2.3 \pm 0.5$ \\
\hline \multicolumn{7}{|c|}{ Stir Zone } \\
\hline $550,1 \mathrm{~h}$ & $1.7 \pm 0.2$ & $1.6 \pm 0.3$ & $1.3 \pm 0.5$ & $3.0 \pm 0.2$ & $2.8 \pm 0.3$ & $2.3 \pm 0.5$ \\
\hline $650,1 \mathrm{~h}$ & $1.6 \pm 0.7$ & $1.6 \pm 0.1$ & $1.4 \pm 0.4$ & $2.8 \pm 0.7$ & $2.8 \pm 0.1$ & $2.4 \pm 0.4$ \\
\hline $750,1 \mathrm{~h}$ & $1.7 \pm 0.1$ & $1.6 \pm 1.1$ & $1.3 \pm 1.6$ & $3.0 \pm 0.1$ & $2.8 \pm 1.1$ & $2.3 \pm 1.6$ \\
\hline $850,1 \mathrm{~h}$ & $1.7 \pm 0.7$ & $1.6 \pm 0.3$ & $1.3 \pm 0.5$ & $3.0 \pm 0.7$ & $2.8 \pm 0.3$ & $2.3 \pm 0.5$ \\
\hline $950,1 \mathrm{~h}$ & $1.7 \pm 1.7$ & $1.6 \pm 0.5$ & $1.3 \pm 0.3$ & $3.0 \pm 1.7$ & $2.8 \pm 0.5$ & $2.3 \pm 0.3$ \\
\hline $950,100 \mathrm{~h}$ & $1.8 \pm 0.5$ & $1.6 \pm 0.8$ & $1.3 \pm 0.3$ & $3.2 \pm 05$ & $2.8 \pm 0.8$ & $2.3 \pm 0.3$ \\
\hline $950,300 \mathrm{~h}$ & $1.8 \pm 1.2$ & $1.6 \pm 1.7$ & $1.3 \pm 0.8$ & $3.2 \pm 1.2$ & $2.8 \pm 1.7$ & $2.3 \pm 0.8$ \\
\hline \multicolumn{7}{|c|}{ Advancing Zone } \\
\hline $550,1 \mathrm{~h}$ & $1.6 \pm 0.1$ & $1.6 \pm 0.5$ & $1.4 \pm 0.1$ & $2.8 \pm 0.1$ & $2.8 \pm 0.5$ & $2.4 \pm 0.1$ \\
\hline $650,1 \mathrm{~h}$ & $1.6 \pm 0.5$ & $1.6 \pm 0.4$ & $1.4 \pm 0.3$ & $2.8 \pm 0.5$ & $2.8 \pm 0.4$ & $2.4 \pm 0.3$ \\
\hline $750,1 \mathrm{~h}$ & $1.7 \pm 0.1$ & $1.6 \pm 0.6$ & $1.2 \pm 0.3$ & $3.0 \pm 0.1$ & $2.8 \pm 0.5$ & $2.1 \pm 0.3$ \\
\hline $850,1 \mathrm{~h}$ & $1.7 \pm 0.9$ & $1.6 \pm 0.4$ & $1.4 \pm 0.2$ & $3.0 \pm 0.9$ & $2.8 \pm 0.4$ & $2.4 \pm 0.2$ \\
\hline $950,1 \mathrm{~h}$ & $1.7 \pm 0.7$ & $1.6 \pm 0.5$ & $1.4 \pm 0.4$ & $3.0 \pm 0.7$ & $2.8 \pm 0.5$ & $2.4 \pm 0.4$ \\
\hline $950,100 \mathrm{~h}$ & $1.8 \pm 0.1$ & $1.6 \pm 0.2$ & $1.4 \pm 0.3$ & $3.2 \pm 0.1$ & $2.8 \pm 0.2$ & $2.4 \pm 0.4$ \\
\hline $950,300 \mathrm{~h}$ & $1.8 \pm 0.9$ & $1.6 \pm 0.2$ & $1.4 \pm 0.5$ & $3.2 \pm 0.9$ & $2.8 \pm 0.2$ & $2.4 \pm 0.5$ \\
\hline
\end{tabular}

\section{TEM Examination}

TEM specimens were prepared from the base material, and some select friction stir welded and heat treated samples. Thin slices were cut from each condition and subsequently ground down using a Gatan grinder. The final thickness after grinding was in the range of 50 to $100 \mu \mathrm{m}$. Discs of $3 \mathrm{~mm}$ diameter were punched out from these thin foils using a Gatan disc puncher. The jet 
polishing technique in a Fischione twinjet polisher accomplished final thinning of the samples. The electrolyte used in jet polishing was a solution of $80 \%$ methanol and $20 \%$ nitric acid (by volume). The jet polishing was done at $-30{ }^{\circ} \mathrm{C}$ by using dry ice to cool the solution. A current of 25-30 A was maintained during jet polishing to obtain the best TEM samples. TEM specimens were examined using a Phillips CM2000 at an accelerating voltage of $200 \mathrm{kV}$ with focus on the identification and microanalysis of the nanometric oxide dispersoids present in both alloys. From TEM images, types of dispersoids, their size, number density and volume fractions were determined using standard image analysis software (Image J). Figure 7 shows the TEM microstructures of the as received MA754 alloy. The images show very fine oxide particles and their uniform distribution.

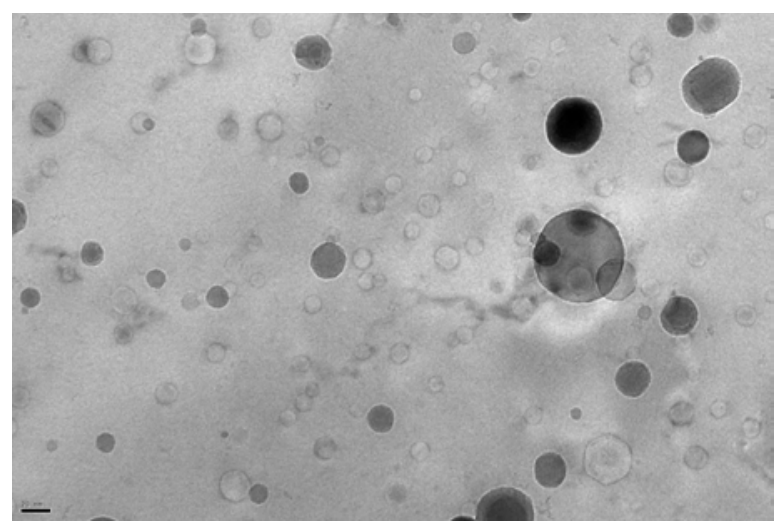

(a) marker scale: $20 \mathrm{~nm}$

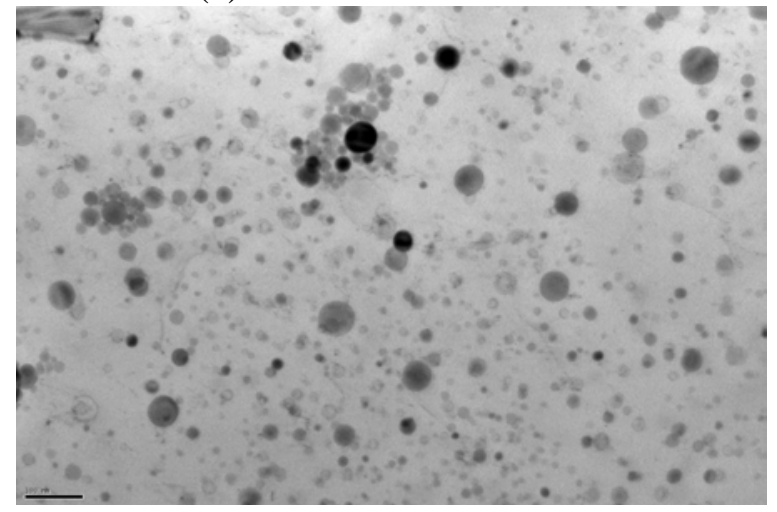

(b) marker scale: $100 \mathrm{~nm}$

Figure 7. TEM microstructures of as received MA754 base materials taken at (a) 50,000X and (b) 20,000X.

Figure 8 shows the EDS results of the base MA754 material. From the EDS maps it is evident the large particles had aluminum in a major percentage and small particles consisted of yttrium mostly and the matrix had Ni mostly. Figure 9 shows the particle size distribution of the same image as shown for EDS. 

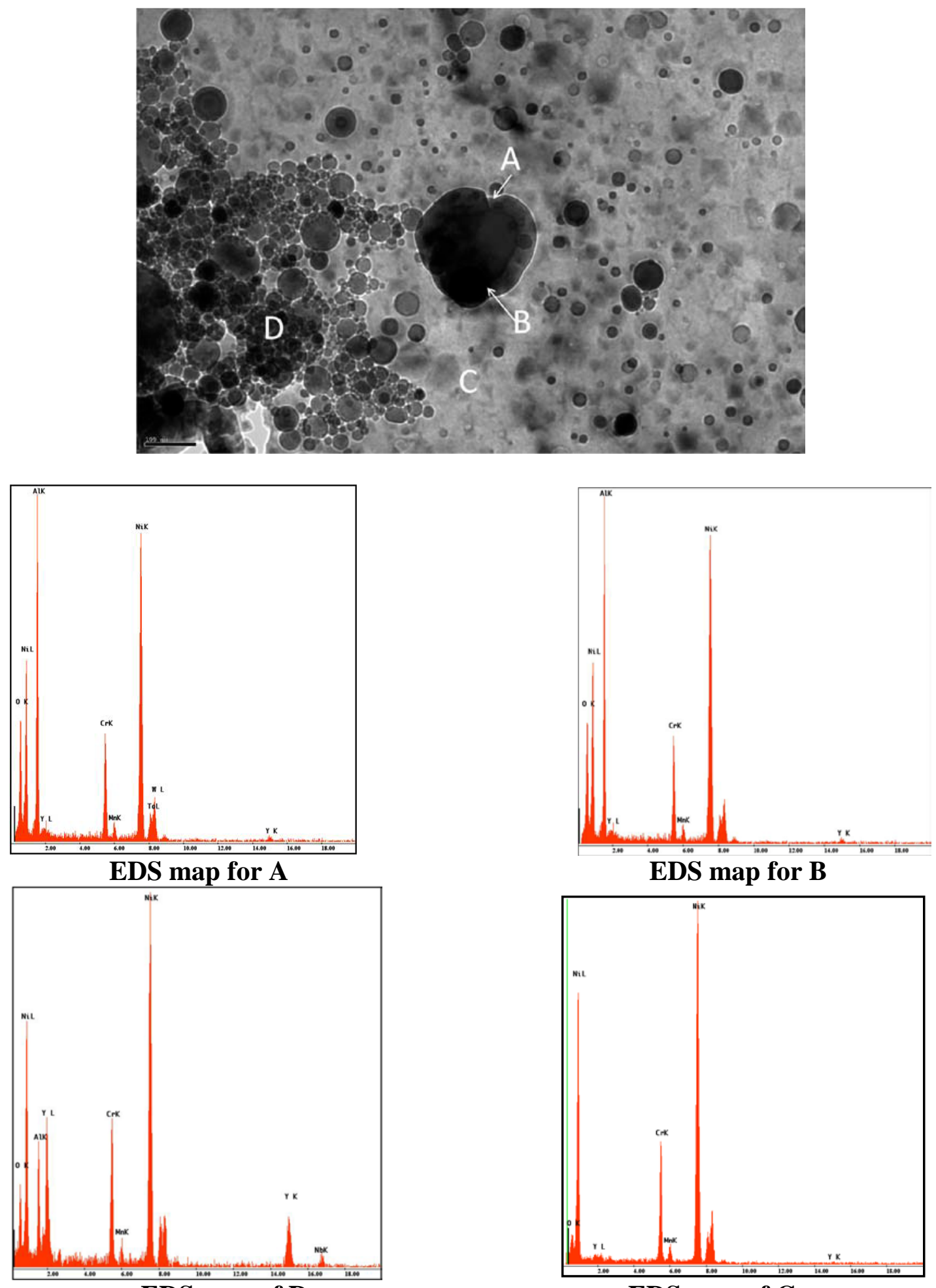

EDS map of D

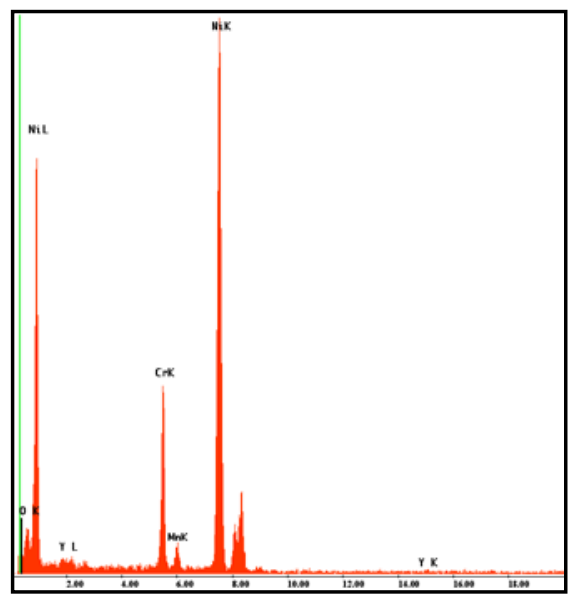

EDS map of $\mathrm{C}$

Figure 8. EDS maps of as received MA754 base material. 


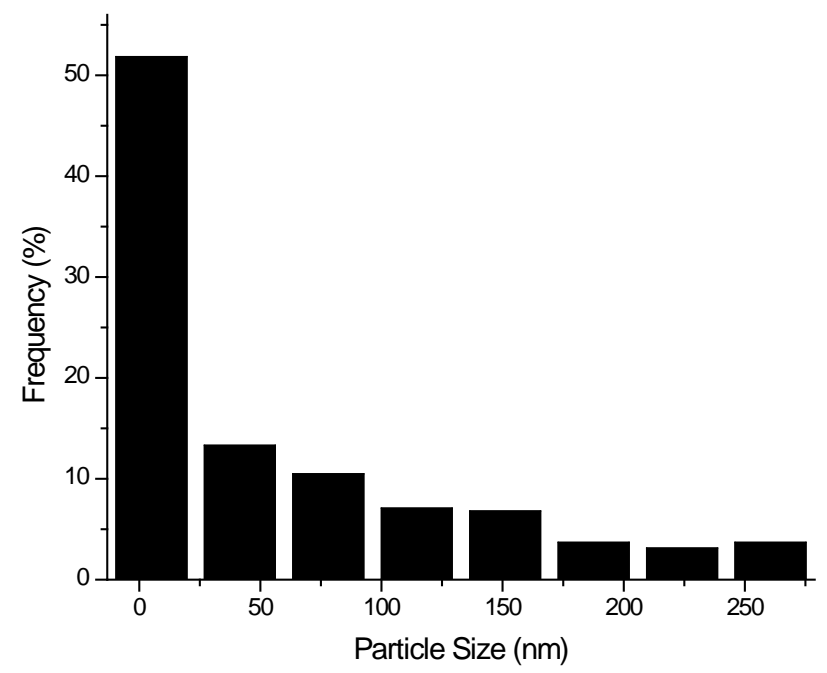

Figure 9. Particle size distribution in MA754 base material

\section{EBSD Studies on MA754 Alloy}

Electron backscatter diffraction (EBSD) studies were conducted at the Boise State University. In order to obtain high quality EBSD images on the MA754 coupons, multiple methods for providing surface relief were explored. In all cases, MA754 was mechanically ground using SiC and diamond solutions prior to placing in a vibratory polisher in either an alumina or silica slurry. In the initial attempts to provide relief on the surface of the FSW MA754 for OIM, it was found that a final polish in colloidal silica gave better optical results than polishing in an alumina slurry. After polishing for 48 hours in a colloidal silica solution on the vibratory polisher, a microstructure could easily be depicted, as shown Fig. 10. The optical microscopy images in Figure 11 shows the microstructure change across the B/C plane of the FSW MA754 coupon. The microstructural relief is seen in optical images as well as with electron microscopy but the confidence of the EBSD image was poor, as shown in the quality index profile of Figure 11b. Figure 11 shows a section on plane D of the MA754 coupon that clearly illustrates a microstructural change between the FSW HAZ and the parent material. In this case, an EBSD and corresponding quality index profile was obtained. However, it is seen in Figure11b that the left side of image has a rather high confidence index while the right side, with the smaller grain size, indexes poorly. 


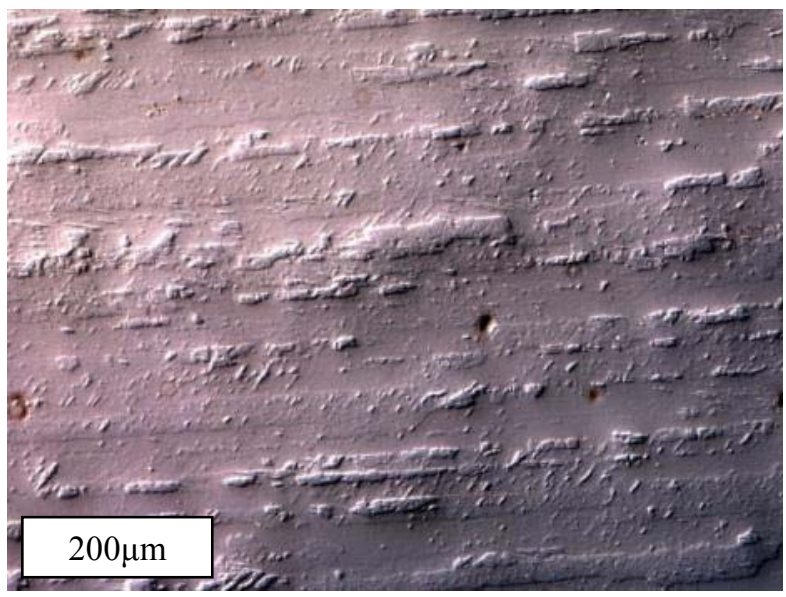

(a)

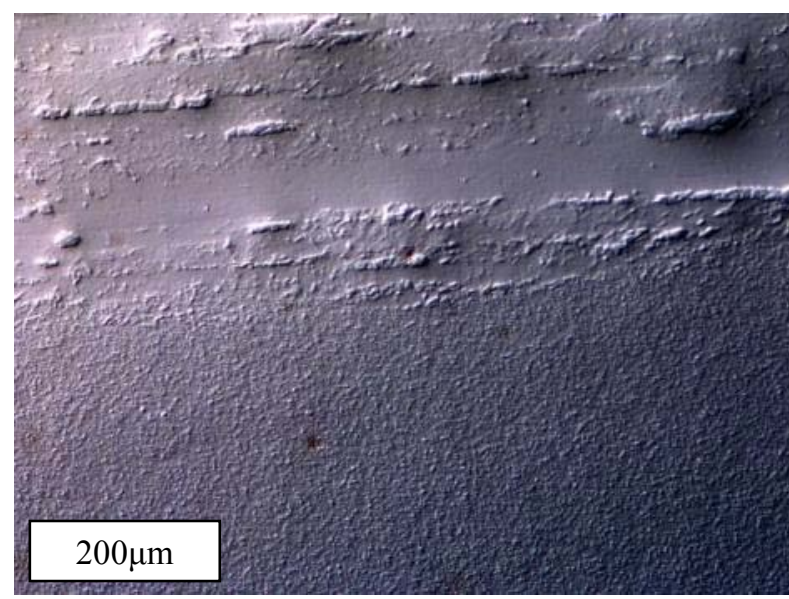

(b)

Figure 10. Optical microscope images of the polished B/C pane of a MA-754 FSW sample. The microstructural relief was created by polishing on a vibratory polisher in a colloidal silica slurry. Image b) shows the difference between the weld affected zone and the parent material.

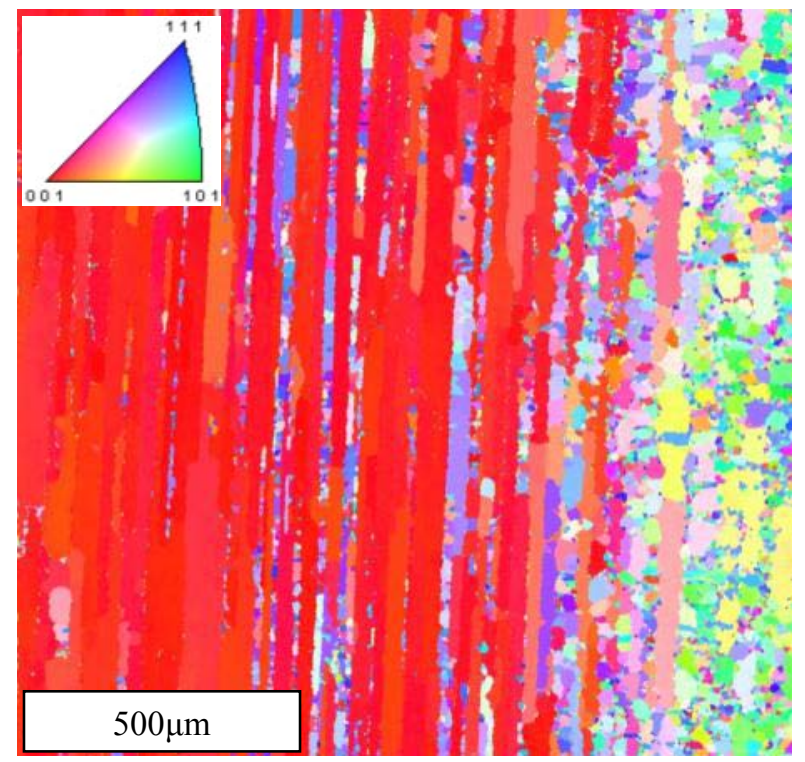

a)

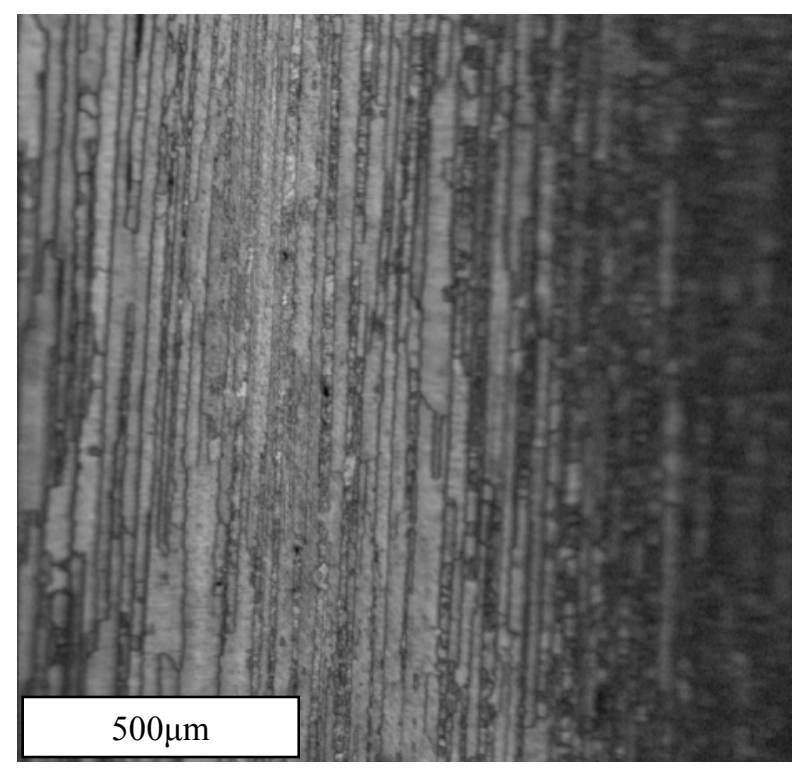

b)

Figure 11. Microstructure of the FSW affected region of MA754 plate. a) Low magnification EBSD image of the weld affected zone, and b) the corresponding quality index profile.

To further characterize the microstructure in the stir region in the middle of the weld region, EBSD data from the central region of MA754 alloy in the transverse cross-section were collected and grain morphology was analyzed (Fig. 12). The EBSD characterization was performed using a LEO 1430VP scanning electron microscope using an EDAX/TSL Digiview III EBSD system. The EBSD data collection was accomplished with an accelerating voltage of $25 \mathrm{kV}$ and a step size varying from $0.1 \mathrm{~mm}$ to $5 \mathrm{~mm}$ (depending on grain size) using TSL OIM Data Collection version 5.0. The data were subsequently analyzed with TSL OIM ${ }^{\mathrm{TM}}$ Analysis 5.0. 

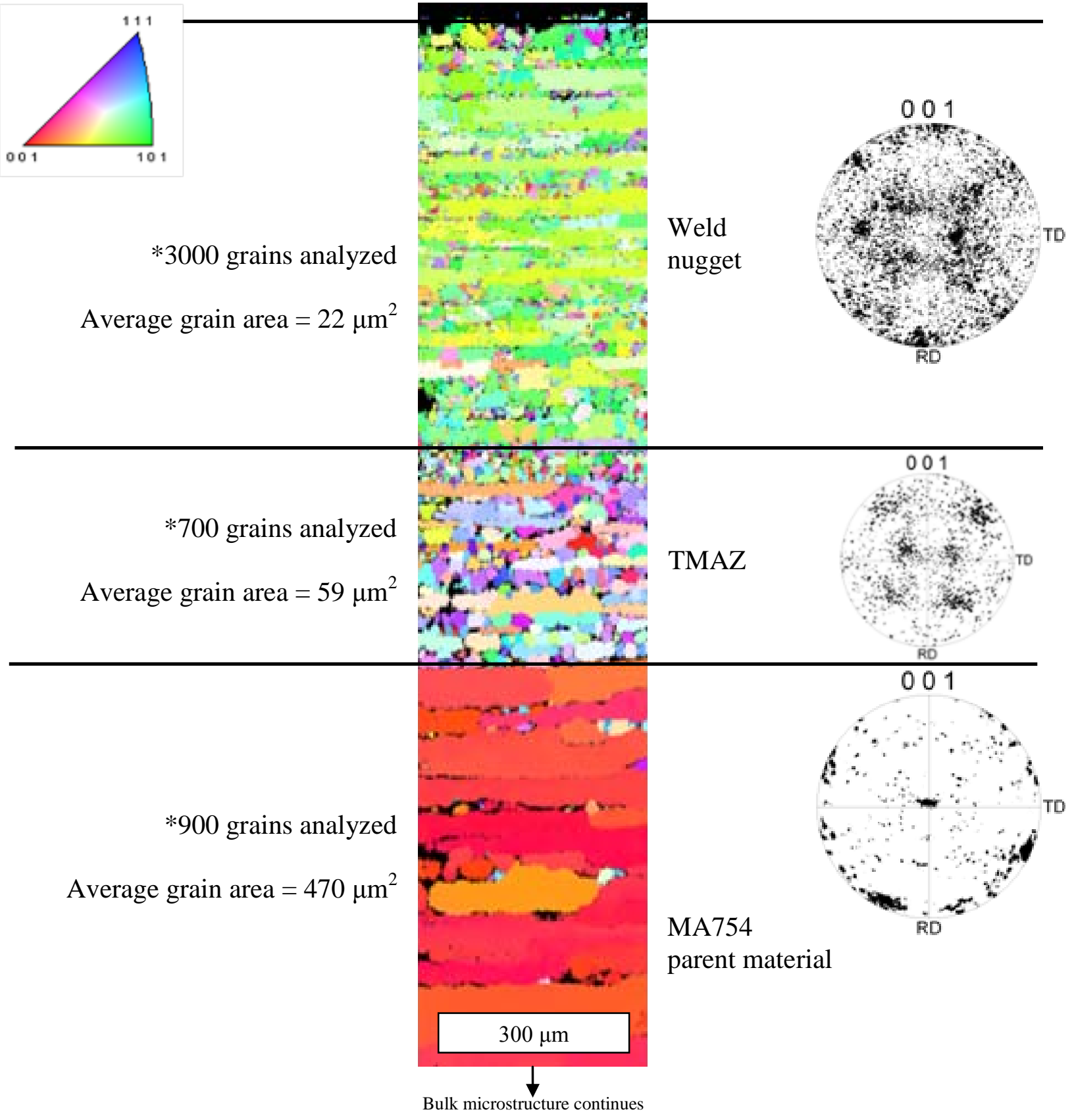

Figure 12. EBSD and grain size analysis through the center of the FSW of the B/C plane of the MA754 coupon. The pole figures of the respective regions (Weld nugget, TMAZ, and bulk MA754) are also shown to the right of the EBSD scan.

Fig. 12 also shows the resulting high quality EBSD image and pole figures from the recorded Kikuchi patterns of the weld nugget, the TMAZ, and the parent MA754 material. As previously mentioned, a typical FSW microstructure includes a TMAZ and a HAZ in the region between the weld nugget and the parent material. However, for this particular sample, a distinct HAZ could not be distinguished between the weld nugget and the parent MA754. The FSW process seemed 
to significantly change the microstructure of the sample to maximum depth of approximately $1 \mathrm{~mm}$. According to the EBSD in Fig. 12, the weld nugget is approximately $670 \mu \mathrm{m}$ and the TMAZ is approximately $300 \mu \mathrm{m}$ at the center of the FSW region. The number of grains included in the EBSD scan and the average grain area of the three identified regions is tabulated in Table 4. It should be noted that the data for the parent MA754 material was obtained from much more data than is shown in the image of Figure 7.

Table 4. Results of OIM analysis through the FSW area described.

\begin{tabular}{|c|c|c|}
\hline Area of interest & $\begin{array}{c}\text { Number of grains } \\
\text { analyzed }\end{array}$ & $\begin{array}{c}\text { Average grain area, } \\
\boldsymbol{\mu m}^{\mathbf{2}}\end{array}$ \\
\hline Weld nugget & 3000 & 22 \\
\hline TMAZ & 700 & 59 \\
\hline Parent MA754 & 900 & 470 \\
\hline
\end{tabular}

The orientation of the grains in the FSW MA754 coupon was evaluated using a Ni:Cr (2.88:1.22) alloy with a cubic crystal structure and a lattice parameter of $3.54 \AA$. From this analysis, it is seen that the large, platelet-like grains of the parent MA754 material are highly oriented towards the $<001>$ directions, which is expected due to typical ODS processing steps. However, it appears that the grains in the weld nugget are highly oriented towards the $<101>$ directions. The grains within the weld nugget itself seem to be randomly oriented. The reasons behind each of these phenomena are not yet understood.

\section{C1.2 MA956 Alloy}

Figure 13 shows an FSW run made on MA956 plate in a bead-on-plate configuration. The maximum temperature at the bottom of the welded region and $2 \mathrm{~mm}$ away from advancing side is about $475-500^{\circ} \mathrm{C}$ and $175-210^{\circ} \mathrm{C}$, respectively. However, it should be noted that accurate measurement of temperature still remains a challenge. Figure 14 shows a cross-section of the welded MA956 alloy with the full nugget (or stir zone) at the center. Figure 15 shows the microstructures of the stir zone the in friction stirred MA956. Grain structure in the stir zone is fine grained and is different from the elongated grain structure that is present in the base material. The grain refinement in the nugget, where fine and equiaxed grains are generated during FSW is attributed to a dynamic recrystallization process due to the combined action of temperature (frictional and adiabatic heating) and high degree of deformation (stirring effect).

The microstructures in the various zones of FSW MA956 reveal that the size of the grains decreases from top to bottom in all the zones. Table 5 lists the grains sizes of all the zones in the friction stirred welded MA956. This difference in sizes is attributed to variation of temperature during the welding. The difference in temperature profile along with difference of stirring time effectively reduces the grain size in various zone of the nugget. 

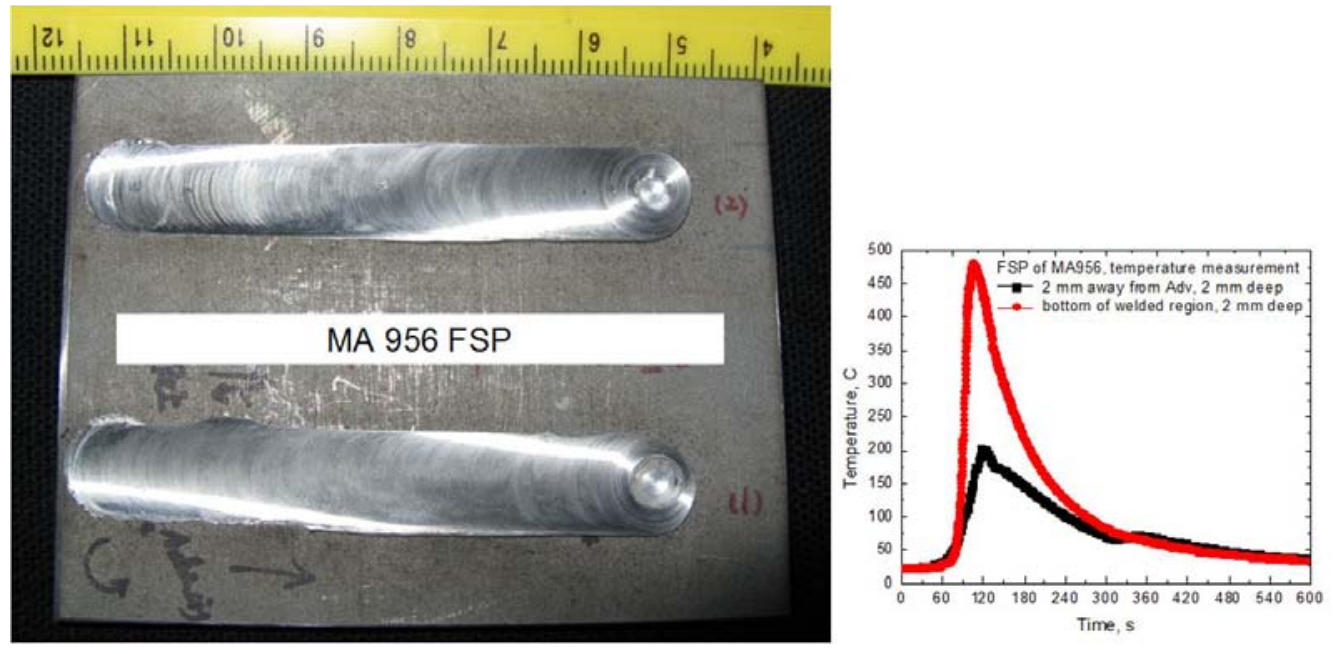

Figure 13. FSW run made on MA956 plate (left) with the corresponding thermal profile during FSW. Note that the actual temperature at the stir zone was higher than shown above.

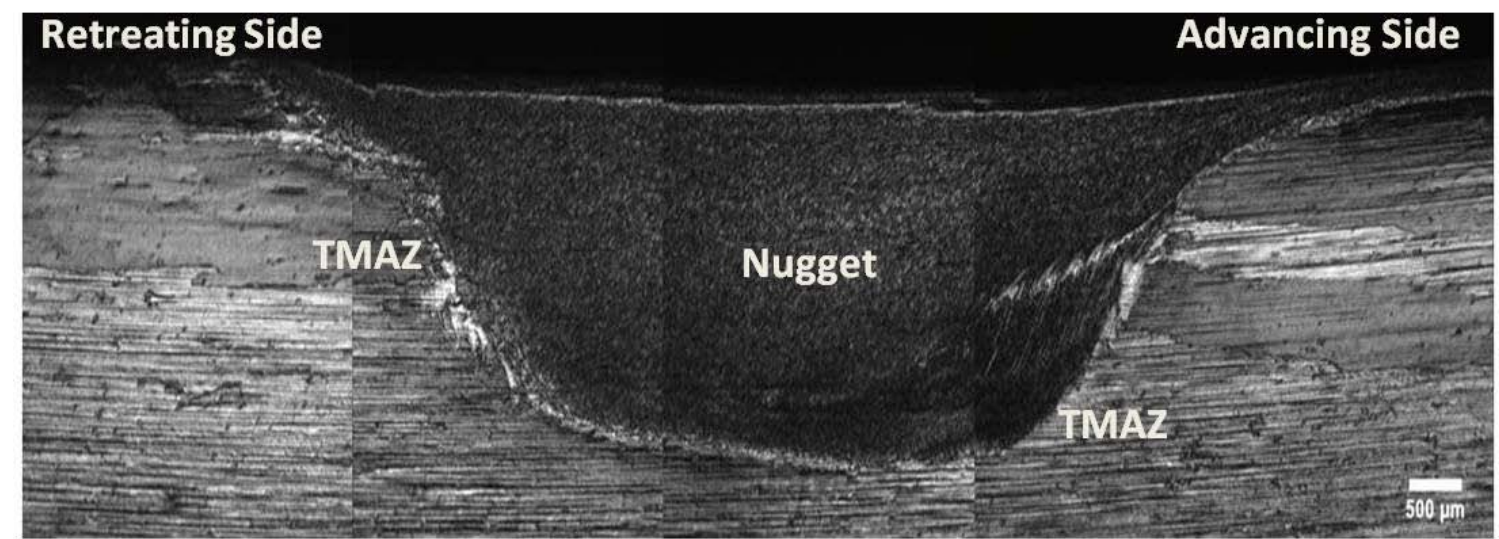

Figure 14. Cross-section of the welded MA956 with the full nugget.

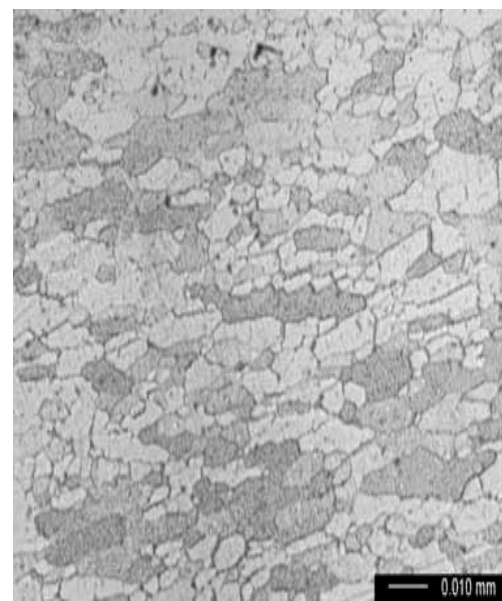

a) Top

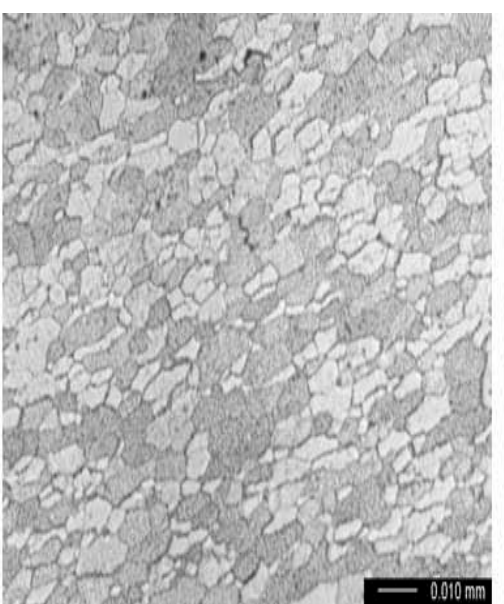

b) Middle

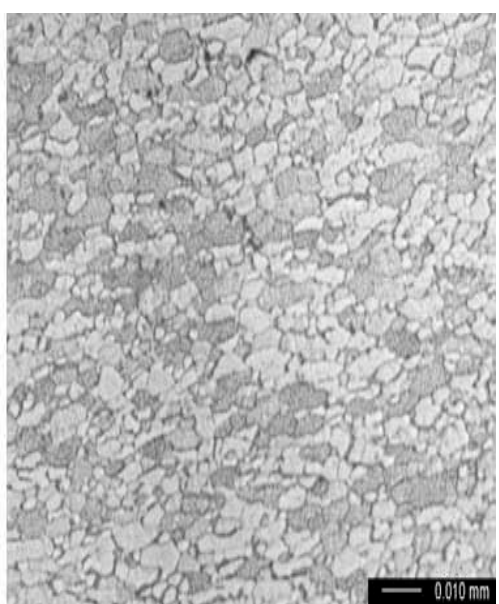

c) Bottom

Figure 15. Grain structure in the stir zone of FSW MA956 alloy. 
Table 5. The Mean Linear Intercept (MLI) and Spatial Grain Size of FSW MA956

\begin{tabular}{|c|c|c|c|c|c|c|}
\hline \multirow[t]{2}{*}{ Condition } & \multicolumn{3}{|c|}{$\begin{array}{l}\text { Mean Linear Intercept (MLI) } \\
\text { Grain Size }(\mu \mathrm{m})\end{array}$} & \multicolumn{3}{|c|}{$\begin{array}{l}\text { Spatial Grain Size } \\
\text { MLI*1.78 }(\mu \mathrm{m})\end{array}$} \\
\hline & Top & Middle & Bottom & Top & Middle & Bottom \\
\hline \multirow{6}{*}{ FSW } & \multicolumn{6}{|c|}{ Retreating Zone } \\
\hline & $3.8 \pm 0.3$ & $3.5 \pm 0.2$ & $3 \pm 0.4$ & $6.7 \pm 0.3$ & $6.2 \pm 0.2$ & $5.3 \pm 0.4$ \\
\hline & \multicolumn{6}{|c|}{ Stir Zone } \\
\hline & $3.9 \pm 0.5$ & $3.7 \pm 0.2$ & $3.3 \pm 0.3$ & $6.9 \pm 0.5$ & $6.5 \pm 0.2$ & $5.8 \pm 0.3$ \\
\hline & \multicolumn{6}{|c|}{ Advancing Zone } \\
\hline & $3.8 \pm 0.3$ & $3.7 \pm 0.1$ & $3.4 \pm 0.1$ & $6.7 \pm 0.3$ & $6.5 \pm 0.1$ & $6.0 \pm 0.1$ \\
\hline
\end{tabular}

The friction stirred samples were subjected to various heat-treatment cycles as listed in Table 6 to study any possible abnormal or normal grain growth which might take place in nugget. The Mean Linear Intercept (MLI) and Spatial Grain Sizes of various zones were calculated to study the possible grain growth. As a reference, heat-treatment of as-received material was also carried out. The optical micrographs in the stir zone of heat-treated FSW MA956 alloy at $950^{\circ} \mathrm{C}$ for 100 and 300h shown in Figs. 16 and 17, respectively, are almost the same as FSW micrographs. No indication of grain growth was observed in the images. The Mean Linear Intercept (MLI) and Spatial Grain Sizes of various zones are given in Table 6 reveal that no significant change was observed, which confirms the stability of the material at high temperatures. Although the grain structure was changed when FSW was carried out, the oxide dispersion present might not have undergone much change after welding.

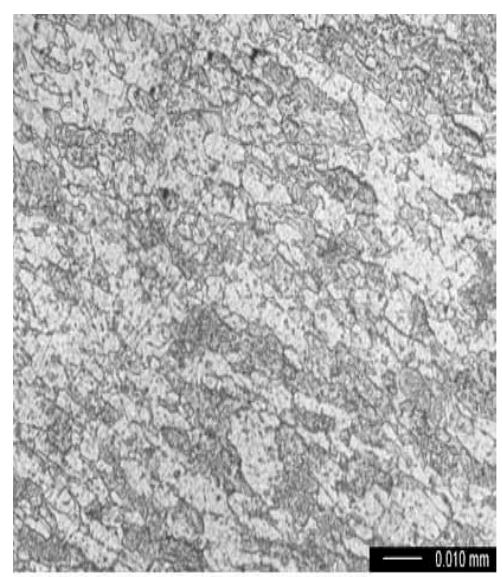

a) Top

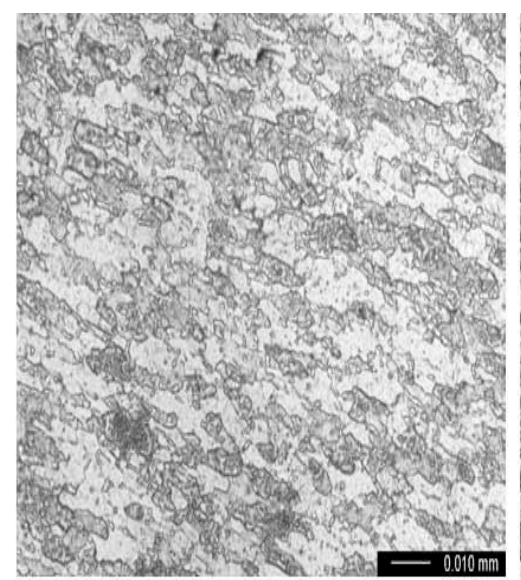

b) Middle

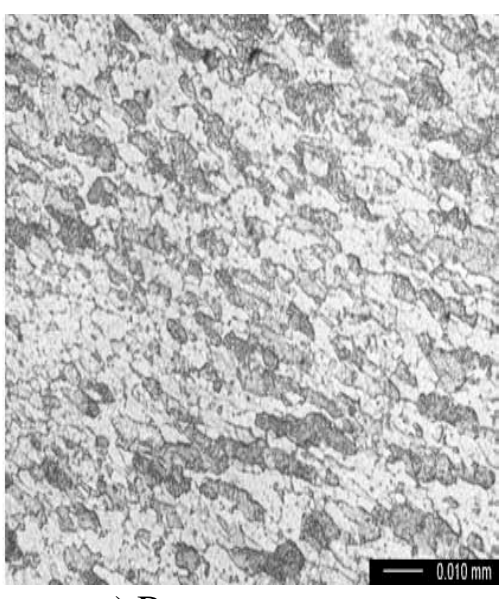

c) Bottom

Figure 16. Grain size distribution in the various zone of heat-treated MA956 at $950^{\circ} \mathrm{C}$ for $100 \mathrm{~h}$. 


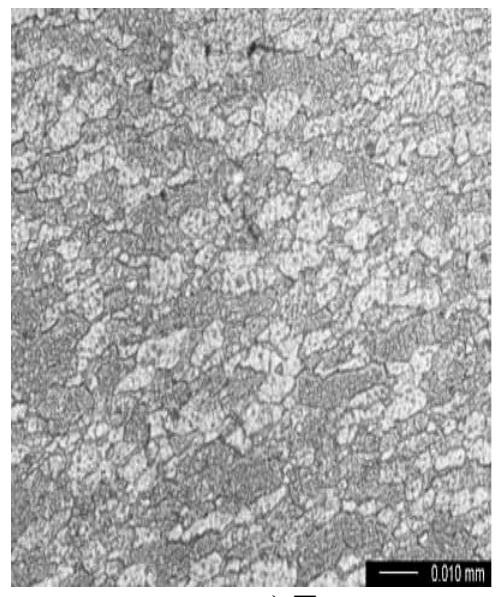

a) Top

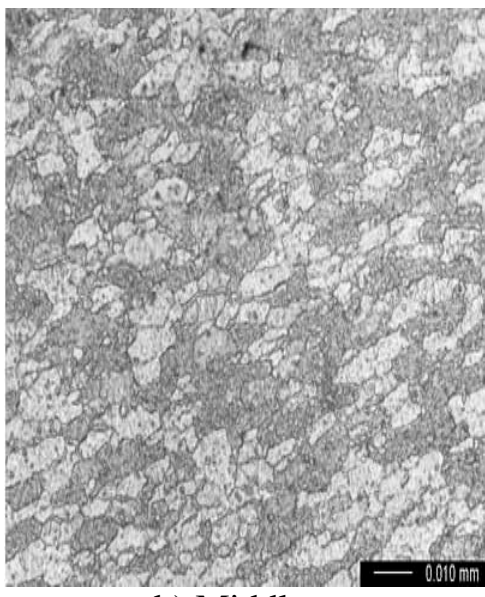

b) Middle

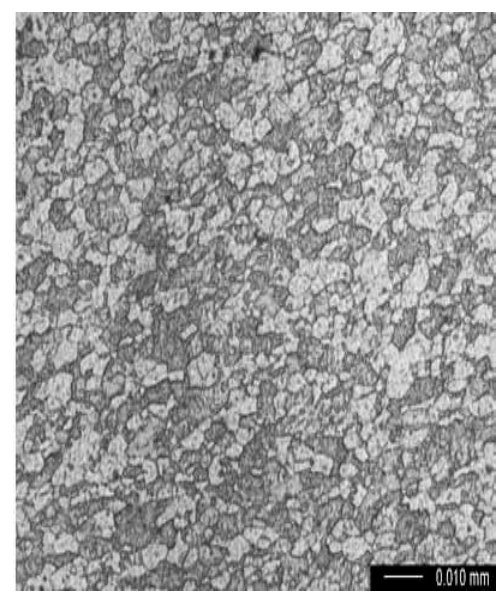

c) Bottom

Figure 17. Grain size distribution in the various zone of heat-treated MA956 at $950^{\circ} \mathrm{C}$ for $300 \mathrm{~h}$.

Table 6. The Mean Linear Intercept (MLI) and Spatial Grain Sizes of FSW MA956

\begin{tabular}{|c|c|c|c|c|c|c|}
\hline \multirow{2}{*}{ Condition } & $\begin{array}{c}\text { Mean Linear Intercept (MLI) } \\
\text { Grain Size (pm) }\end{array}$ & \multicolumn{2}{c|}{$\begin{array}{c}\text { Spatial Grain Size } \\
\text { MLI*1.78 (pm) }\end{array}$} \\
\cline { 2 - 7 } & Top & Middle & Bottom & Top & Middle & Bottom \\
\hline \multicolumn{7}{|c|}{ Retreating Zone } \\
\hline $\mathbf{5 5 0 , 1 h}$ & $3.8 \pm 0.4$ & $3.5 \pm 2.3$ & $3.3 \pm 0.7$ & $6.7 \pm 0.4$ & $6.2 \pm 2.3$ & $5.8 \pm 0.7$ \\
\hline $\mathbf{6 5 0 , 1 h}$ & $3.7 \pm 1.1$ & $3.5 \pm 0.8$ & $3.2 \pm 1.7$ & $6.5 \pm 1.1$ & $6.2 \pm 0.8$ & $5.6 \pm 1.7$ \\
\hline $\mathbf{7 5 0 , 1 h}$ & $3.8+0.8$ & $3.6 \pm 1.4$ & $3.5 \pm 0.2$ & $6.7 \pm 0.8$ & $6.4 \pm 1.4$ & $6.2 \pm 0.2$ \\
\hline $\mathbf{8 5 0 , 1 h}$ & $3.8 \pm 0.1$ & $3.5 \pm 0.3$ & $3.5 \pm 0.6$ & $6.7 \pm 0.1$ & $6.2 \pm 0.3$ & $6.2 \pm 0.6$ \\
\hline $\mathbf{9 5 0 , 1 h}$ & $3.8 \pm 1.3$ & $3.7 \pm 0.7$ & $3.4 \pm 0.8$ & $6.7 \pm 1.3$ & $6.5 \pm 1.3$ & $6.0 \pm 0.8$ \\
\hline $\mathbf{9 5 0 , 1 0 0 h}$ & $3.9 \pm 0.3$ & $3.7 \pm 1.3$ & $3.3 \pm 0.2$ & $6.9 \pm 0.3$ & $6.5 \pm 1.3$ & $5.8 \pm 0.2$ \\
\hline $\mathbf{9 5 0 , 3 0 0 h}$ & $3.9 \pm 0.4$ & $3.7 \pm 0.5$ & $3.3 \pm 0.8$ & $6.9 \pm 0.4$ & $6.5 \pm 0.5$ & $5.8 \pm 0.8$ \\
\hline \multicolumn{7}{|c|}{ Stir Zone } \\
\hline $\mathbf{5 5 0 , 1 h}$ & $3.9 \pm 0.7$ & $3.8 \pm 0.2$ & $3.6 \pm 1.1$ & $6.9 \pm 0.7$ & $6.7 \pm 0.2$ & $6.4 \pm 1.1$ \\
\hline $\mathbf{6 5 0 , 1 h}$ & $3.8 \pm 3.1$ & $3.6 \pm 0.1$ & $3.4 \pm 0.4$ & $6.7 \pm 3.1$ & $6.4 \pm 0.1$ & $5.7 \pm 0.4$ \\
\hline $\mathbf{7 5 0 , 1 h}$ & $3.8 \pm 3.0$ & $3.7 \pm 0.7$ & $3.5 \pm 0.1$ & $6.7 \pm 3.0$ & $6.5 \pm 0.7$ & $6.2 \pm 0.1$ \\
\hline $\mathbf{8 5 0 , 1 h}$ & $3.8 \pm 1.4$ & $3.7 \pm 0.4$ & $3.6 \pm 0.2$ & $6.7 \pm 1.4$ & $6.5 \pm 0.4$ & $6.4 \pm 0.2$ \\
\hline $\mathbf{9 5 0 , 1 h}$ & $3.9 \pm 0.5$ & $3.8 \pm 0.2$ & $3.6 \pm 0.3$ & $6.9 \pm 0.5$ & $6.7 \pm 0.2$ & $6.4 \pm 0.3$ \\
\hline $\mathbf{9 5 0 , 1 0 0 h}$ & $3.9 \pm 1.1$ & $3.8 \pm 0.3$ & $3.6 \pm 1.7$ & $6.9 \pm 1.1$ & $6.7 \pm 0.3$ & $6.4 \pm 1.7$ \\
\hline $\mathbf{9 5 0 , 3 0 0 h}$ & $3.9 \pm 0.8$ & $3.9 \pm 0.1$ & $3.7 \pm 0.4$ & $6.9 \pm 0.8$ & $6.9 \pm 0.1$ & $6.5 \pm 0.8$ \\
\hline \multicolumn{7}{|c|}{ Advancing Zone } \\
\hline $\mathbf{5 5 0 , 1 h}$ & $3.7 \pm 0.6$ & $3.7 \pm 0.1$ & $3.6 \pm 1.3$ & $6.5 \pm 0.6$ & $6.5 \pm 0.1$ & $6.4 \pm 1.3$ \\
\hline $\mathbf{6 5 0 , 1 h}$ & $3.8 \pm 3.0$ & $3.7 \pm 0.5$ & $3.6 \pm 0.7$ & $6.7 \pm 3.0$ & $6.5 \pm 0.5$ & $6.4 \pm 0.7$ \\
\hline $\mathbf{7 5 0 , 1 h}$ & $3.7 \pm 0.3$ & $3.7 \pm 0.2$ & $3.6 \pm 1.3$ & $6.5 \pm 0.3$ & $6.5 \pm 0.2$ & $6.4 \pm 1.3$ \\
\hline $\mathbf{8 5 0 , 1 h}$ & $3.8 \pm 1.1$ & $3.7 \pm 0.9$ & $3.6 \pm 2.1$ & $6.7 \pm 1.1$ & $6.5 \pm 0.9$ & $6.4 \pm 2.1$ \\
\hline $\mathbf{9 5 0 , 1 h}$ & $3.8 \pm 0.5$ & $3.7 \pm 0.3$ & $3.6 \pm 0.8$ & $6.7 \pm 0.5$ & $6.5 \pm 0.3$ & $6.4 \pm 0.8$ \\
\hline $\mathbf{9 5 0 , 1 0 0 h}$ & $3.8 \pm 0.9$ & $3.8 \pm 0.1$ & $3.6 \pm 0.5$ & $6.7 \pm 0.9$ & $6.7 \pm 0.1$ & $6.4 \pm 0.5$ \\
\hline $\mathbf{9 5 0 , 3 0 0 h}$ & $3.9 \pm 1.2$ & $3.8 \pm 0.7$ & $3.7 \pm 0.4$ & $6.9 \pm 1.2$ & $6.7 \pm 0.7$ & $6.5 \pm 1.2$ \\
\hline
\end{tabular}




\section{TEM Studies on MA956 Alloy}

Fig. 18 shows a lower magnification TEM micrograph of as received MA956 base material. From these images, grain boundaries and oxide precipitates present in very small size and their uniform distribution is clearly visible.

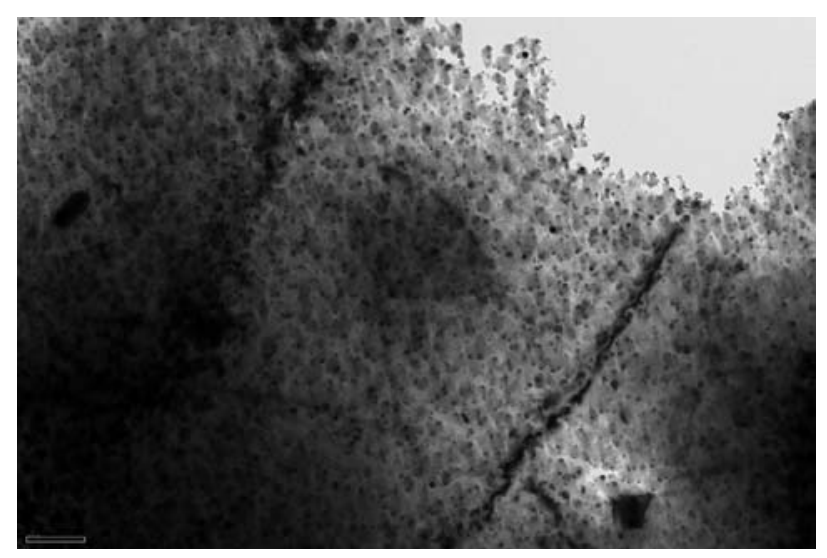

Figure 18. A low magnification TEM microstructures of as-received MA956 base material (3800X, marker scale: $500 \mathrm{~nm}$ for all images).

Figure 19 taken at a magnification of $8800 \mathrm{X}$ shows the much finer details of the oxide dispersion in the base material. Figures 19 shows the TEM microstructures of as received material taken at magnification of $50000 X$. From these images it is observed that the oxide particles are very much uniformly distributed and less than $50 \mathrm{~nm}$ in size. From the images it was also observed that the oxide dispersions were present either uniformly distributed or else they were in clusters of agglomeration as shown in Figure 20.

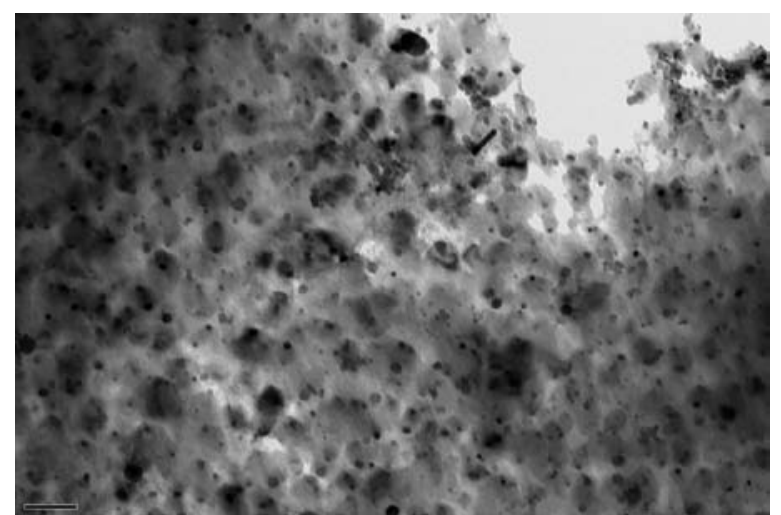

Figure 19. TEM microstructure of as-received MA956 base material (8800X, marker scale: 200nm). 


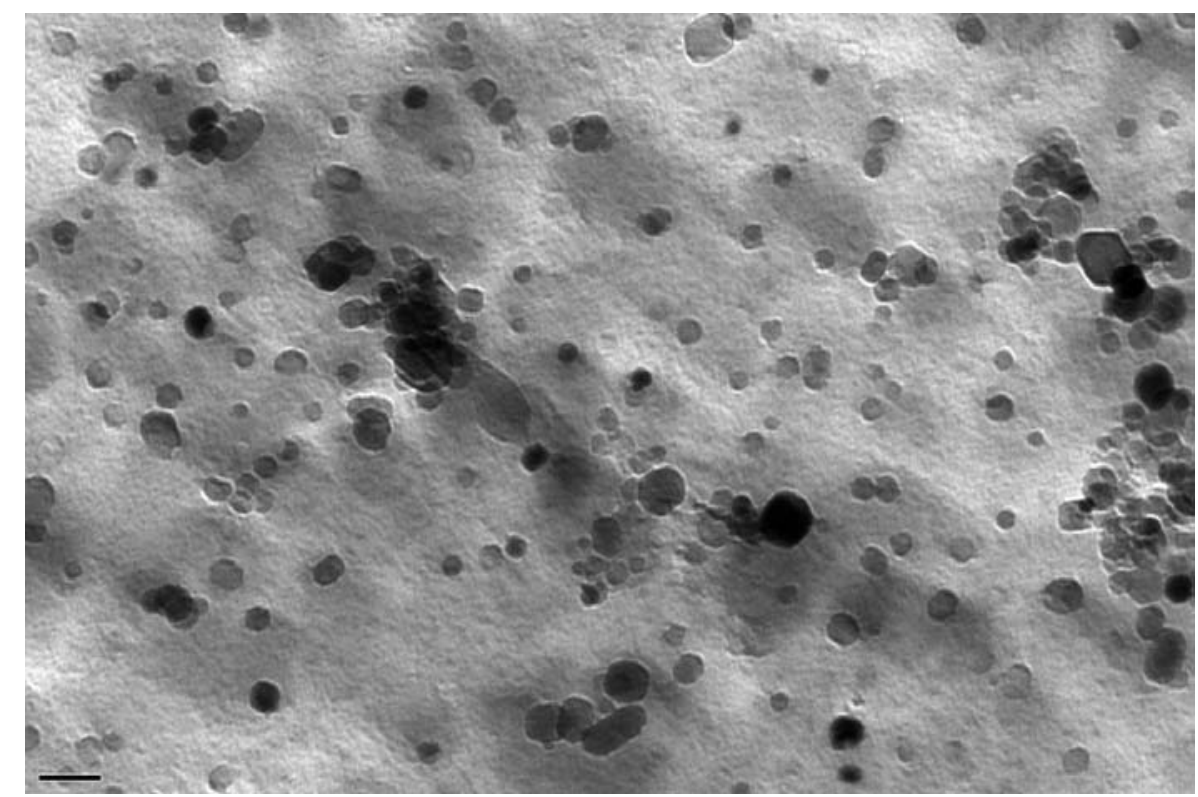

Figure 20. TEM microstructure of as-received MA956 base material showing various types in which dispersions are present (27500X, marker scale: 50nm).

The TEM microstructure of friction stir welded MA956 is shown in Fig. 21. With reference to TEM microstructure of the base material, it was observed that fine grains were formed. From Fig. 21, it is observed that the distribution of oxide particles was very less in welded sample. Moreover very fine particles disappeared indicating that agglomeration of oxide particles taking place during welding.

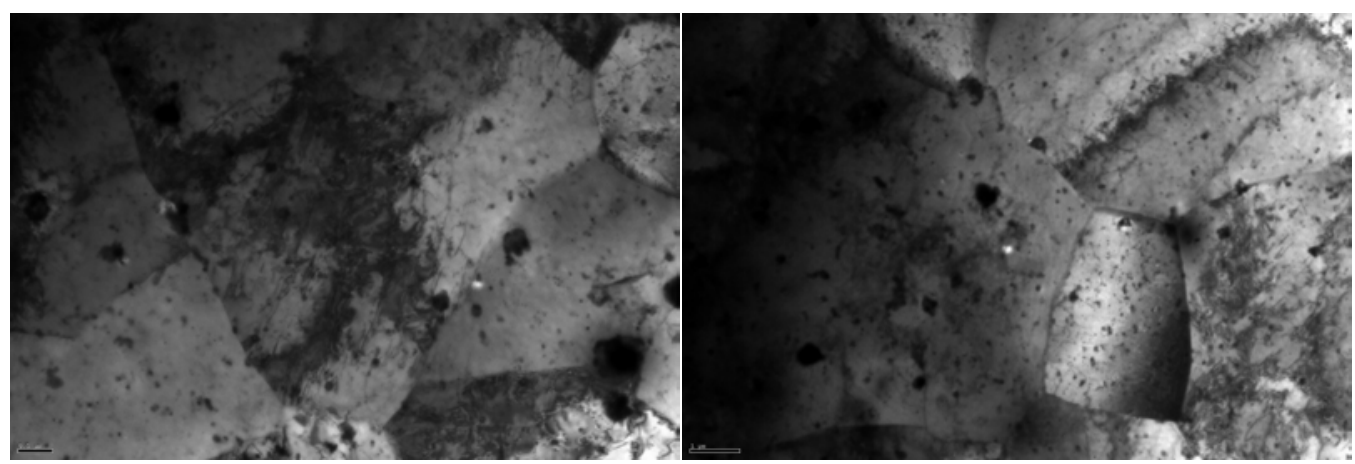

(a) 2000X (marker scale: 500nm)

(b) $2800 \mathrm{X}$ (marker scale: 1000nm)

Figure 21. TEM microstructures of FSW MA956 alloy. 
(a) 2000X (marker scale: 1000nm)

(b) 2000X (marker scale: 500nm)

(c) $3800 \mathrm{X}$ (marker scale: $500 \mathrm{~nm}$ )

Figure 22. TEM microstructures of FSW MA956 alloy.

The EDS results of friction stir welded MA956 are shown in Figure 23. The particles A and B mainly consisted of Ti along with Fe, Al, Cr, and Y. Whereas $\mathrm{C}$ had mostly Y peaks but the strong Fe and $\mathrm{Cr}$ peaks came from the matrix. Maps of $\mathrm{M}$ showed strong peaks Fe and $\mathrm{Cr}$ confirming the composition of the matrix. Fig. 24 shows the particle size distribution in FSW MA956 alloy calculated from the TEM images obtained. 

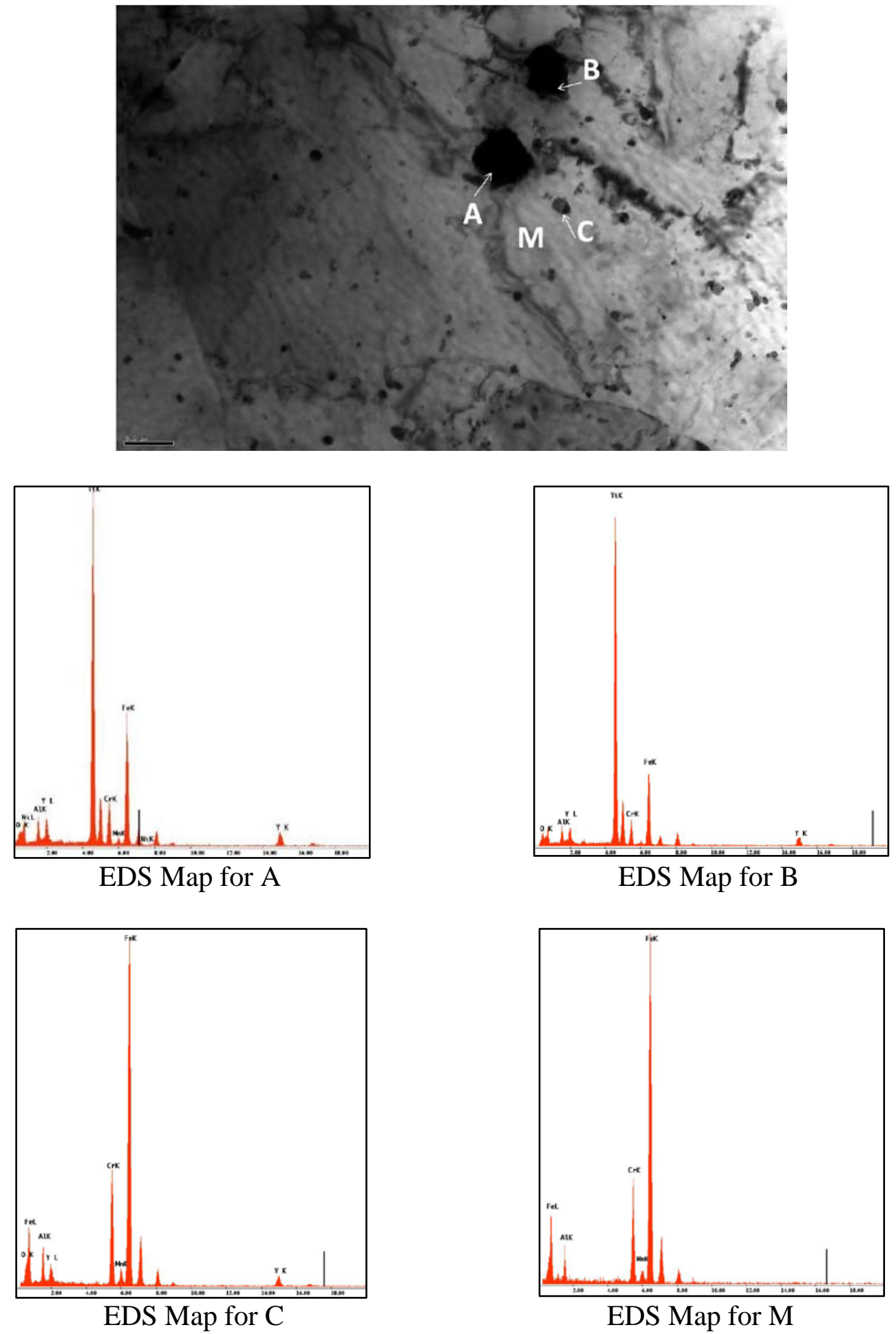

Figure 23. EDS spectra of Friction Stir welded MA956 alloy. 


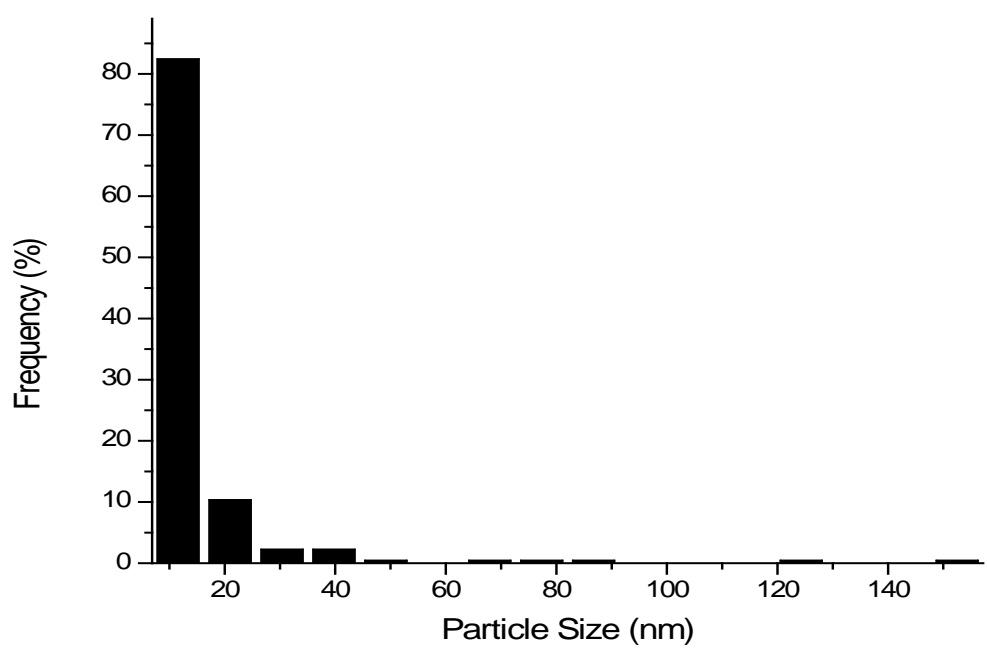

Figure 24. Particle size distribution in FSW MA956 alloy.

\section{EBSD Studies on MA956 Alloy}

Similar to the study on the FSW MA754 coupons, FSW MA956 coupons were also created by the Center for Friction Stir Processing, Missouri University of Science and Technology using a WC-Co cermet tool. The microstructural changes from the FSW on the MA956 were characterized using micro hardness testing, optical microscopy, electron microscopy, and OIM using EBSD. Similar to the MA754 study, the MA956 required multiple iterations to provide surface relief for optical and electron imaging including EBSD. The sample cross-section (Fig. 25a) were mechanically ground to 800 grit using $\mathrm{SiC}$ paper, polished with a $6 \mu \mathrm{m}$ diamond slurry, and then further polished with a vibratory polisher in a $0.05 \mu \mathrm{m}$ colloidal silica slurry for 12-24 hours. The resultant surface relief is seen in Figure 25c. The sample was then ion milled using the same settings described above to obtain an image as shown in Figure 25b. In order to obtain the best optical images, the FSW MA956 was etched for 30 seconds in a $\mathrm{H}_{2} \mathrm{O}: \mathrm{HCl}(1: 1)$ solution.

As seen in the images of Fig. 25, a distinct microstructural change exists between the weld nugget and the parent MA956 material. The macro image of the B/C plane of the coupon (shown in Fig. 25a) shows a distinct weld nugget and transition region into the MA754 parent material. It should be noted that the macro and optical images were obtained after the micro hardness testing was complete, thus leaving an equally spaced $(300 \mu \mathrm{m})$ pattern of indents. The optical microscopy images more closely show the interface regions between the TMAZ and the weld nugget on what is presumed to be the retreating edge (Fig. 25b) and the advancing edge (Fig. 25c) of the FSW. An interesting observation in Fig. 25b of what appears to be agglomerates at the interface between the weld nugget and the bulk MA956. The agglomerates are shown by the arrows in the figure. 


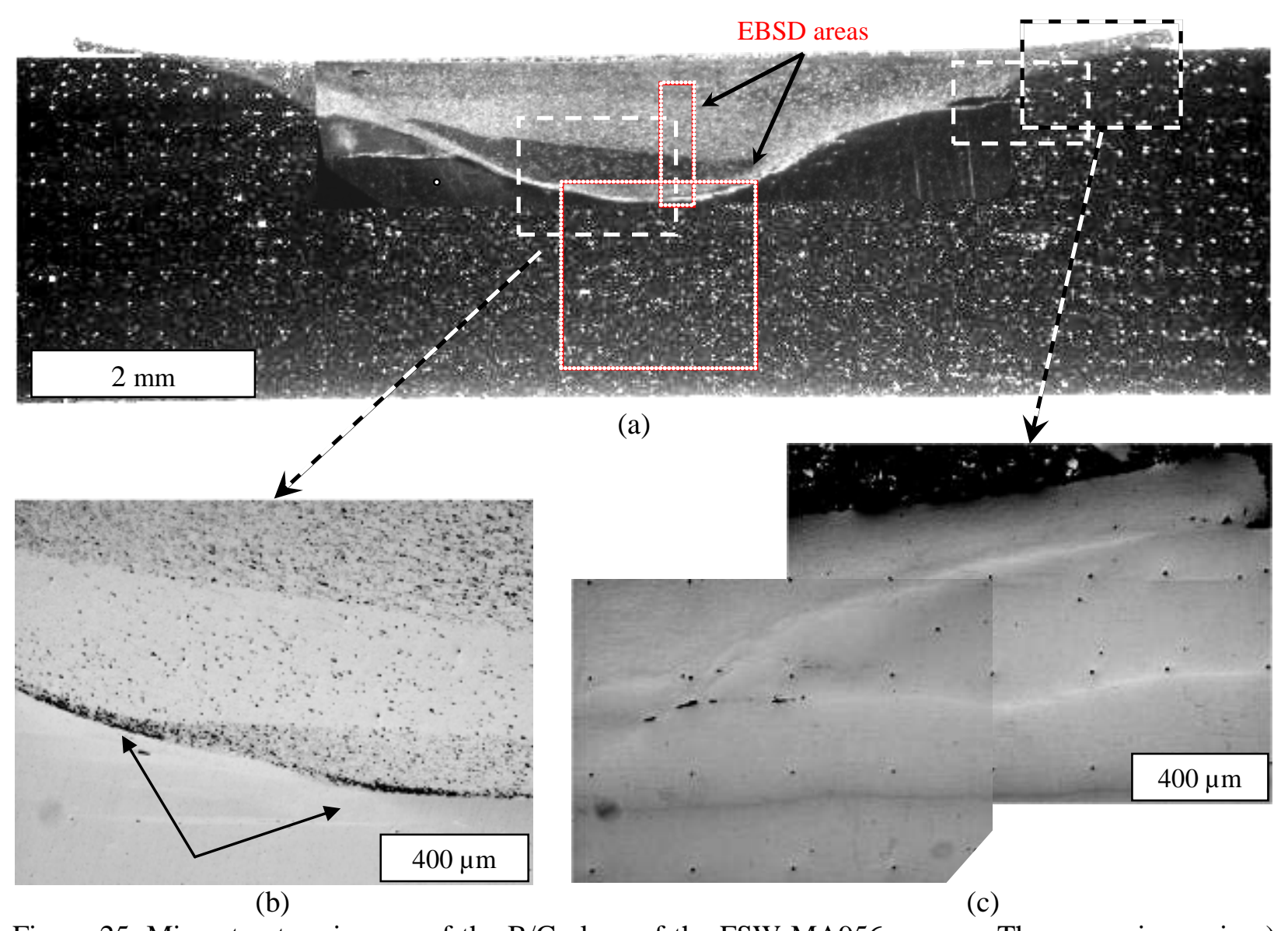

Figure 25. Microstructure images of the B/C plane of the FSW MA956 coupon. The macro image in a) shows a distinct weld nugget and HAZ from the FSW process. Optical microscopy images of the presumed b) retreating edge and c) advancing edge of the FSW weld nugget show distinct changes in the microstructure due to the FSW process.

As with the FSW MA754, further microstructural characterization of the FSW MA956 coupons included microhardness testing as per ASTM E-384 on the same LECO microhardness tester under similar conditions (square pyramidal diamond indenter tip, 300 gram load, 13 second dwell, and $300 \mu \mathrm{m}$ square grid). The data were collected on the B/C plane of the FSW MA956, as shown above in above. The resulting microhardness map is superimposed on an optical microscope image (Fig. 26). Although a general hardness trend is observed over the weld nugget and HAZ, notice that the relative hardness changes very little between the weld nugget and the parent material: less than $75 \mathrm{HV}$. It is also worth noting that a lower hardness is observed in the weld nugget than in the bulk MA754. This is interesting because the weld nugget has a much smaller grain structure than the bulk material, as shown in the OIM below. The average hardness of the bulk MA956 plate was found to be approximately $270 \mathrm{HV}$, which agrees well with the literature of a heat treated MA956 plate (265 HV). 


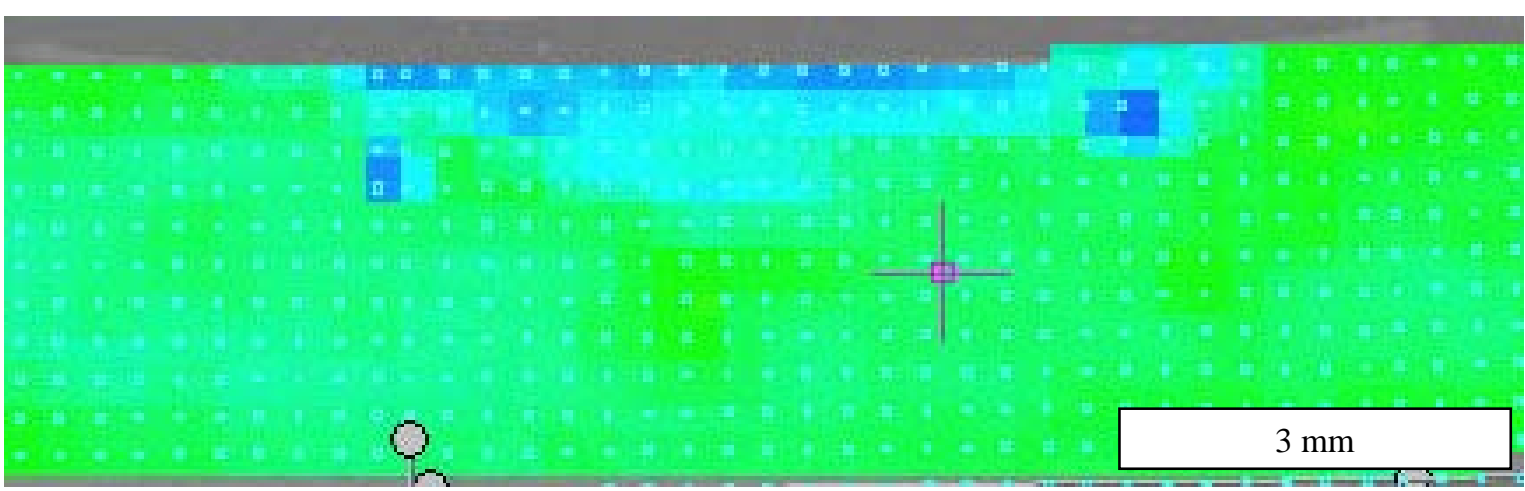

Figure 26. Microhardness map superimposed on an optical microscope image of the $B / C$ plane of the FSW MA956 coupon. The microhardness map was created as per ASTM E-384 and has a resolution of $300 \mu \mathrm{m}$.

Although it is not presented here, an elemental map of the weld nugget was completed and on the scale used, there were no noticeable oxide agglomerations or phase segregations in the weld nugget, TMAZ, or the bulk material. To further characterize the microstructure of the FSW region in the middle of the weld region, EBSD of the area shown in of Fig. 25a was collected and grain morphology was analyzed (Fig. 27). The OIM characterization was performed using the same SEM and EBSD equipment as with the FSW MA754 samples (previously described). Figure 10 shows a collage of the resulting EBSD scans through the center of the FSW zone of the MA956 coupon. From these scans, three regions were identified, namely: the weld nugget, the TMAZ, and the parent MA956 material. As with the FSW MA754 sample, a distinct HAZ could not be distinguished.

The orientations of the grains in the FSW MA956 coupon were evaluated using a cubic $\alpha$-Fe structure with a lattice parameter of $(2.87 \AA)$. The MA956 parent material microstructure is apparent from the highly textured, large, platelet-like grain structure. This type of microstructure is expected due to the typical ODS processing steps. The parent material exhibits a very strong crystallographic texture, as seen in the corresponding pole figure. The TMAZ region also exhibits very strong texture but in a different crystallographic direction, and the weld nugget appears to be predominately randomly textured. Also, literature suggests that as the grain size decreases, the hardness increases in as-received MA956. However, in the work presented here, the opposite was observed: the grain size of the weld nugget was much smaller than the bulk ODS plate, but the hardness decreased, as was seen by other research (Legendre et al. JNM, 2009). It is plausibly due to the changes in precipitate morphology and texture in the material. One might also notice that the grains in the TMAZ and the weld nugget seem to be elongated in a diagonal down right direction which is typical of a friction welding process due to the "forging" action on the welded materials. 


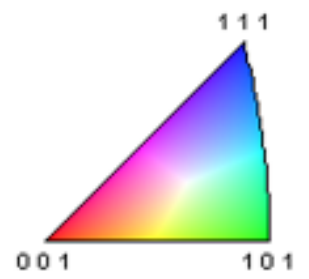

*3600 grains analyzed

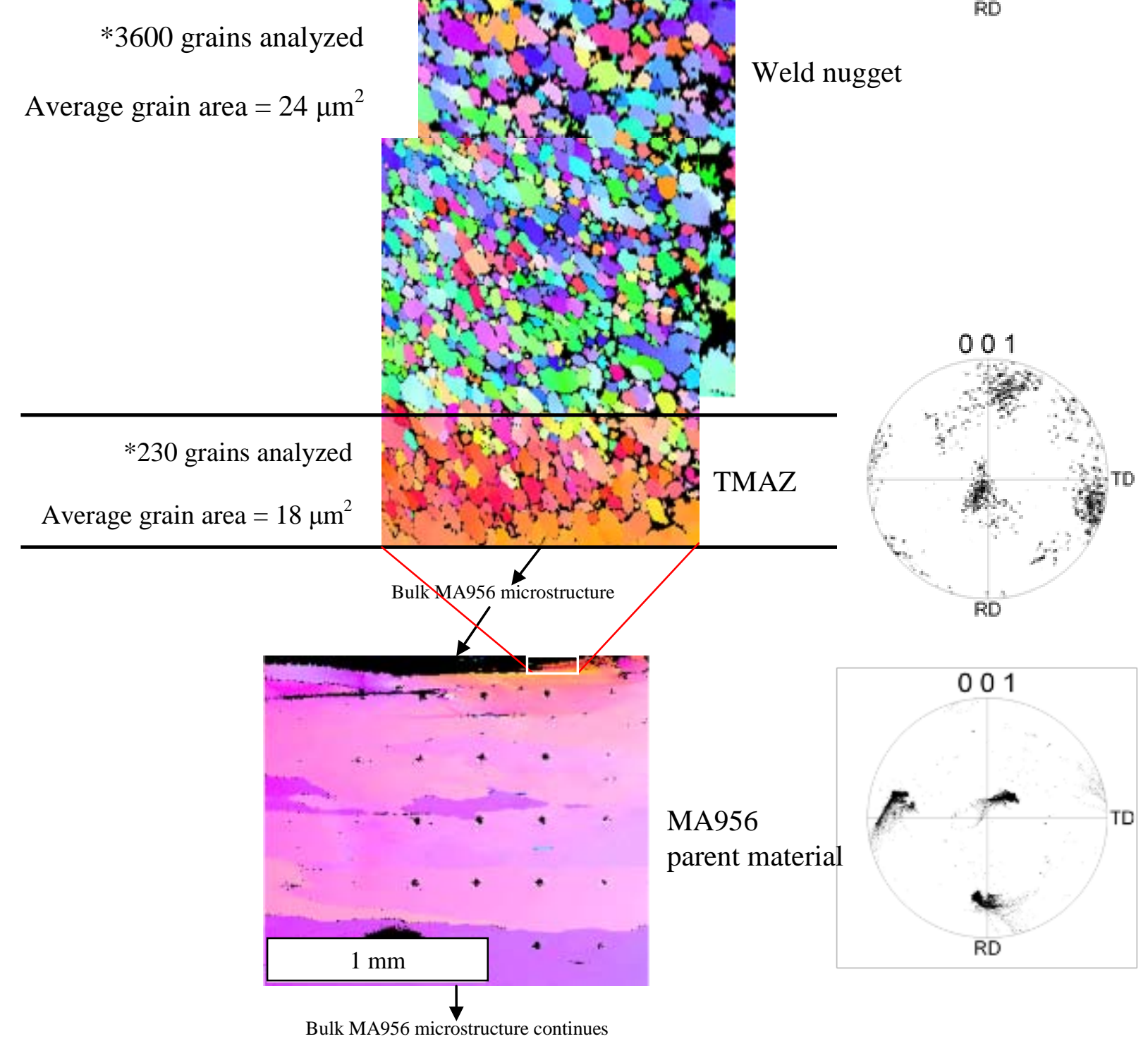

Weld nugget microstructure continues

Figure 27. EBSD and grain size analysis through the center of the FSW of the B/C plane of the MA956 coupon. The pole figures of the respective regions (Weld nugget, TMAZ, and bulk MA956) are also shown to the right of the EBSD scan. The scan was collected in the area in shown in Figure 25a. 


\section{C2. Pressure Resistance Welding}

\section{Materials}

In this study, MA957 alloy cladding tubes having an outer diameter of $6.9 \mathrm{~mm}$ and HT-9 alloy cylindrical rods (also termed as the end plug) having an outer diameter of $7.9 \mathrm{~mm}$ were used for creating the first set of PRW welds. Also, a set of PRW welds were made between MA754 and HT-9 plates. The nominal compositions of MA957 and MA754 are given in Table 7, and the same is given for the HT-9 alloy in Table 8 .

Table 7. Compositions in percent by wt.\%

\begin{tabular}{cccccccc}
\hline & $\mathrm{Fe}$ & $\mathrm{Ni}$ & $\mathrm{Cr}$ & $\mathrm{Mo}$ & $\mathrm{Ti}$ & $\mathrm{Al}$ & $\mathrm{Y}_{2} \mathrm{O}_{3}$ \\
\hline MA754 & - & Bal. & 20 & - & 0.5 & 0.3 & 0.60 \\
MA957 & Bal. & - & 14 & 0.3 & 1.0 & - & 0.25 \\
\hline
\end{tabular}

Table 8. HT-9 alloy composition in wt.\%

\begin{tabular}{cccccccccc}
\hline & Fe & C & Cr & Mo & Mn & V & W & Ni & Si \\
\hline HT9 & Bal. & 0.2 & 12 & 1 & 0.6 & 0.25 & 0.5 & 0.5 & 0.4 \\
\hline
\end{tabular}

\section{Weld Development}

A PRW machine was acquired from the Centerline, Windsor, Canada, utilizing the grant. PRW is basically a resistance welding technique that can be employed to perform solid-state joining of metallic materials, by carefully controlling its operational parameters. The PRW process is straightforward and is based on the simple Joule heating principle (Equation 1), coupled with a high axial joining force.

$$
H=I^{2} R \cdot t
$$

where $H$ is taken to be the heat generated $(J), I$ is the current $(A), R$ is the resistance $(\Omega)$, and $t$ is the current flow time (s). Equation 1 can be taken as true if I and $\mathrm{R}$ remains relatively constant for the entire length of $t$. By controlling these variables, it is the goal of this study to obtain the most optimal weld possible.

The PRW unit utilizes a 3-phase, $60 \mathrm{~Hz}$ Voltza ${ }^{\circledR}$ Transgun designed and built by Centerline Ltd. based out of Windsor, Canada. The unit installed at the Center for Advanced Energy Studies (CAES-Idaho Falls, ID) is a "C" style transgun, based on the positions of the electrodes (Fig. 28). The unit uses an $\mathrm{OMHA}^{\circledR}$ activator cylinder, which is responsible for the hydraulic powered force. Connected in line with the hydraulic cylinder is the electrode ram and water-cooled fixture, along with the adjacent electrode water-cooled fixture. The opposing electrode is connected to the lower electrode arm, which is linked to the transformer, completing the electron flow path. The transformer is powered by a $480 \mathrm{~V}$ line voltage, controlled by the welders control unit. Finally, a handheld device called the Medar, acting as the brains of the PRW, controls the welder, which programs the executable variables and records operational data. 


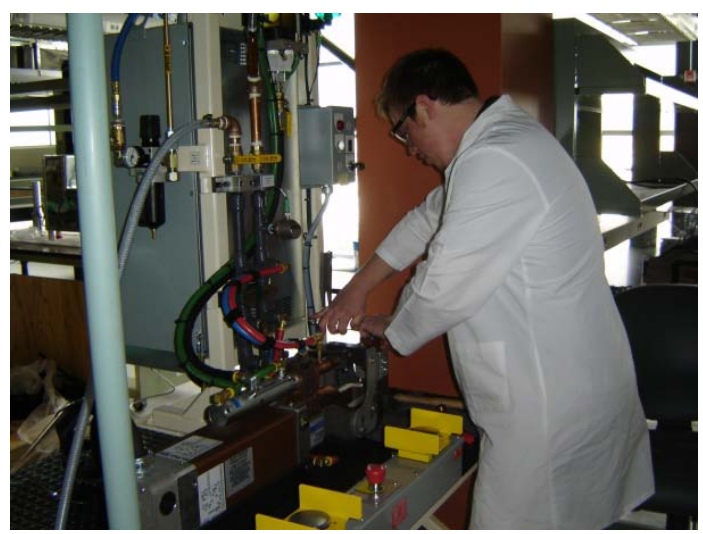

Figure 28. A view of the PRW equipment (a graduate student, Nathan Jerred, working on it).

When preparing to perform a weld the specimens are placed within each electrode fixture, allowing precise protrusion lengths from the fixture surface of $2.54 \mathrm{~mm}$ and $1.27 \mathrm{~mm}$ for the end-plug and cladding tube fixtures, respectively. Once the welding cycle is initiated the electrode ram forces contact between the specimens, at about $0.689 \mathrm{MPa}$, at which time current is applied for a variable amount of time. Simultaneously, the hydraulic cylinder applies a squeeze force of about 6.89 MPa, to promote a forging of the two interfaces of the specimens. In order to minimize variability, the stick-out length and forging force has thus far been maintained, thus allowing for the current and applied time to be varied. The PRW process involves two phases, an initial softening phase where the applied current causes Joule heating of the specimens interface, and a subsequent joining phase where the secondary intensified force from the hydraulic cylinder promotes forging of the two interfaces. In this capacity, this welding method is similar to upset welding because the forging force causes the softened interfaces to experience a high degree of deformation. This deformation is deemed a quality due to the conjecture that oxidized surfaces are forced away from the final welding interface, leaving a higher quality bulk weld. Once a successful weld has been completed, the specimen is categorized based on the executed variables and processed for further characterization. When the weld parameters are fully optimized to produce quality welds, further testing will be done to fully characterize the mechanical integrity of the welds. Note that the PRW joints between MA754 and HT-9 alloys were created at the Centerline facility in Windsor, Canada.

\section{Weld Characterization}

Although several characterization techniques are currently being utilized to better understand the fundamental aspects of the PRW welds, results of a few of the characterization techniques are reported here. Optical microscopy of the weld cross-sections were performed using standard metallographic practices and simple bend tests have been carried out to determine the mechanical integrity of the MA957/HT-9 PRW joints. Room temperature and elevated temperature (up to $700{ }^{\circ} \mathrm{C}$ ) burst testing using internal gas (argon) pressurization in the range of 2,000-10,000 psi were performed to understand the stress-rupture properties of similarly welded joints. A view of the burst testing set-up used at North Carolina State University is shown in Figure 29.

The pressure resistance welded joints between MA754 and HT-9 plates were characterized using standard metallographic techniques at the Boise State University. The final polish of the joints 
was completed with a diamond slurry in a vibratory polisher. The joints were characterized using optical microscopy as well electron backscatter diffraction (EBSD) in a LEO 1430VP scanning electron microscope (SEM). The EBSD data was collected with an EDAX/TSL Digiview III detector and was analyzed with TSL Orientation Imaging Microscopy (OIM ${ }^{\mathrm{TM}}$ ) Analysis 5.31. The EBSD OIM ${ }^{\mathrm{TM}}$ analysis allowed for determination of grain orientation within a selected area of the sample. The specimen was tilted to $70^{\circ}$ and scanned at $25 \mathrm{kV}$ accelerating voltage with a magnification between 100 and 150, which resulted in scan areas of approximately $1 \mathrm{~mm}^{2}$. The step size of the scans was set at $2.5 \mu \mathrm{m}$.

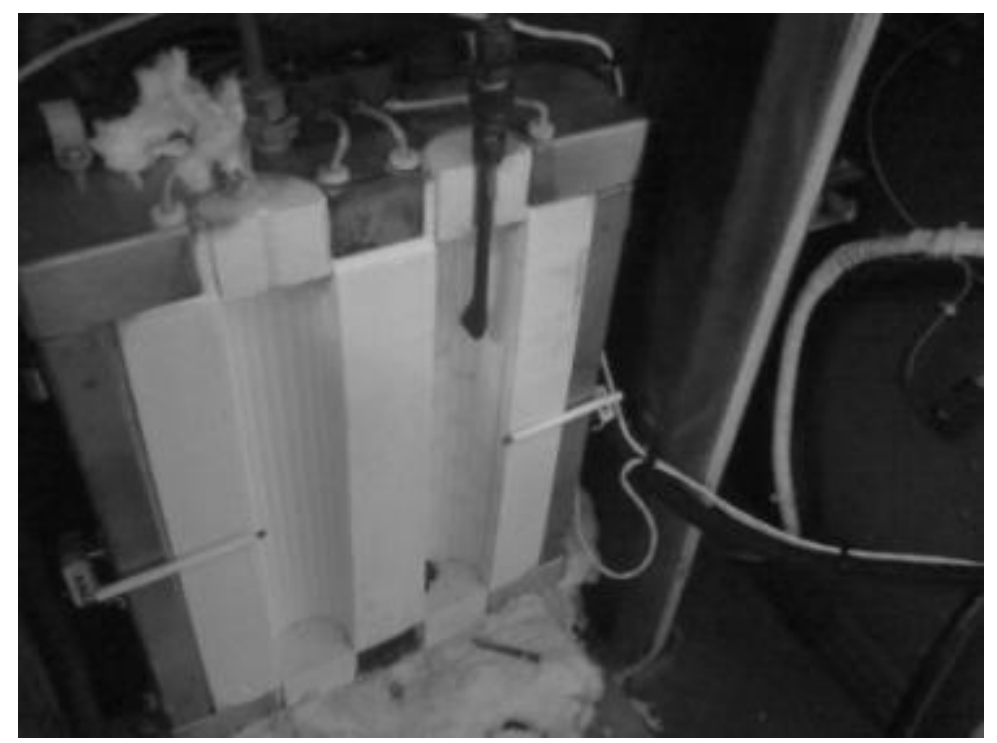

Figure 29. A view of the burst testing furnace with a failed specimen inside.

Compact tension specimens were electro-discharge machined while keeping the weld interface near the crack-tip. The data attained from these tests will keep a measure of the crack growth rates of the welded specimens during fatigue cycling at constant stress intensity factor and stress ratio $(\mathrm{R}=0.1)$. The direct current potential drop (DCPD) technique was used to track the crack length.

\section{Process Optimization}

The PRW equipment has been continuously modified to better suit requirements for this research. Numerous welds have been completed between HT-9 cylindrical end-plugs and MA957 cladding tubes, which together simulate a completed fuel pin. Although the optimization phase is still underway, optical micrographs have shown positive results. Figure 5 shows a crosssectional view of a PRW MA957/HT-9 joint that was created at $1000 \mathrm{lb}$ force, $17 \mathrm{kA}$ current, 2 primary welding cycles, a hold period of 10 cycles and a final squeeze cycle of 5 cycles. These joints were also tested for mechanical integrity. These samples were first welded at the Centerline facility in Windsor outside the scope of the ongoing weld optimization scheme. The weld zone microstructure appears to be free from any porosity and the grain structure seems to be non-dendritic. This is in contrast to what was observed in the fusion weld of MA957 alloy as shown in Fig. 1. Welding of these fuel pin specimens have been completed with varying currents ranging from 7,000 to 25,000 A at varying times ranging from 33 to 55 ms. Table 9 lists weld parameters used in the ongoing optimization process and the relevant observations. As can be 
seen, the forging pressure and time was maintained at $800 \mathrm{lbs}$ and 5 cycles (83 ms), respectively, while the current and welding time was varied. Although welding time has thus far been varied, 2 cycles (33 ms) seems to be an ideal welding time, thus allowing the effect of current to be documented, further minimizing the variability. The capabilities of the PRW are also being tested, welding with different types of current applying functions. One function includes starting at lower current inputs and increasing to a high limit over a defined time interval. Another technique includes an impulse function where current is applied a defined number of times with a defined cooling period between each impulse. More PRW runs and characterization has been made, and will be made available in the journal papers under preparation.

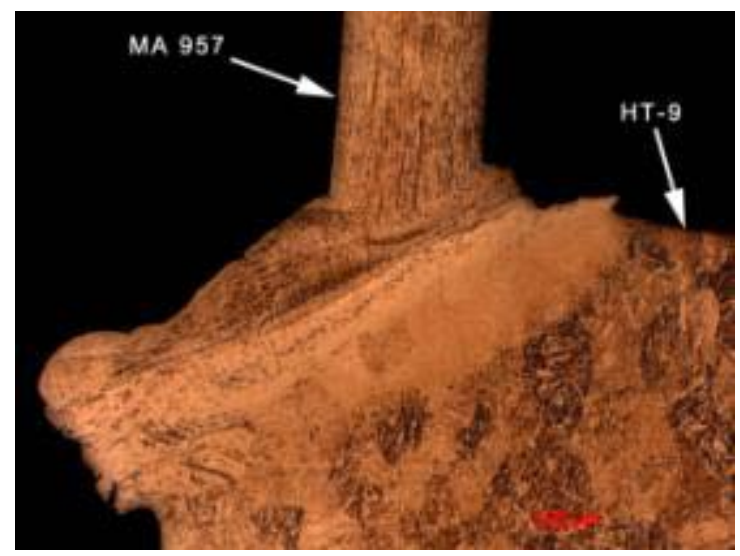

(a)

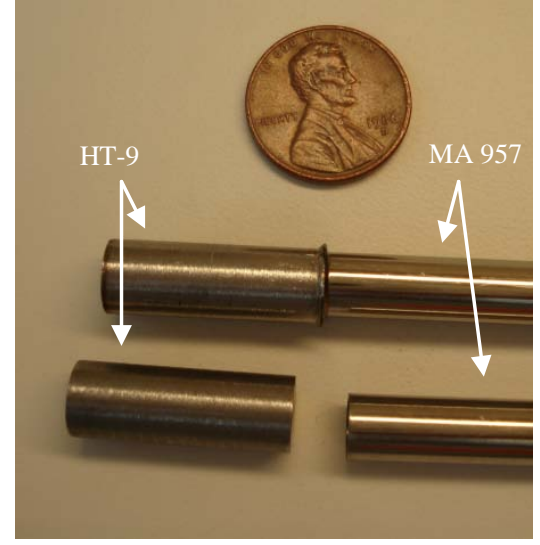

(b)

Figure 30. a) An optical micrograph of the PRW joint cross-section. b) A MA957 tube - HT9 end plug PRW joint.

Table 9. PRW executed parameters taken from the Medar

\begin{tabular}{ccccccl}
\hline $\begin{array}{c}\text { Sampl } \\
\text { e No. }\end{array}$ & $\begin{array}{c}\text { Force } \\
\text { (lbs) }\end{array}$ & $\begin{array}{c}\text { Forge } \\
\text { Time } \\
\text { (cycles) }\end{array}$ & $\begin{array}{c}\text { Weld } \\
\text { Time } \\
\text { (cycles) }\end{array}$ & $\begin{array}{c}\text { Voltag } \\
\text { e } \\
(\mathrm{V})\end{array}$ & $\begin{array}{c}\text { Current } \\
(\mathrm{kA})\end{array}$ & \multicolumn{1}{c}{ Comments } \\
\hline 1 & 800 & 5 & 2 & 461 & 15.85 & Welded, interface is distinguishable \\
2 & 800 & 5 & 2 & 471 & 7.34 & No bonding of interfaces \\
3 & 800 & 5 & 2 & 465 & 13.52 & Good weld \\
4 & 800 & 5 & 3 & 468 & 11.39 & Welded, w/ slight oxidation of surface \\
\hline
\end{tabular}

\section{Process Simulation}

The multiphysics program COMSOL is being used to model the joule heating phenomena occurring at the joint interfaces. The fixtures and specimens have been modeled within the program, which can be used to approximate temperatures at the interfaces depending on the current and time selected. Computational analysis can be modified between the differing material specimens, based on material property inputs into the program. The forging force can also be modeled within the COMSOL program, yielding an approximate deformation of the specimens based on temperature, force and material property inputs. Overall, the COMSOL modeling is used for preliminary approximation of possible parameter inputs of the welding control unit, to aid in determining a more fixed parameter range. A preliminary simulation view using tungsten specimens is shown in Fig. 31. Further work is in progress to apply the developed simulation technique for PRW runs in ODS alloys. 


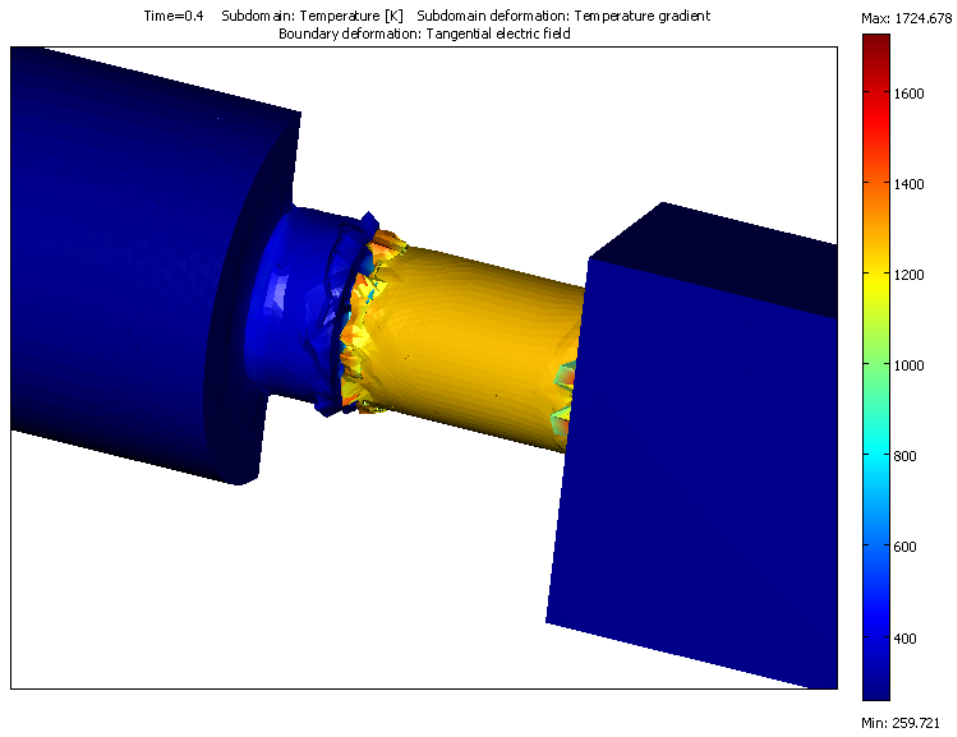

Figure 31. Preliminary simulation of joule heating within COMSOL. Force induced deformation is not included in the simulation.

\section{Mechanical Integrity Tests for MA957-HT9 Joints}

Simple mechanical bend tests were carried out on the MA957/HT-9 PRW joints. Although no quantitative properties were estimated from these tests, it demonstrated that the PRW joints were strong enough to avoid any fracture at the weld zone; even at a nearly $90^{\circ}$ bend angle. A view of two bend-tested specimens is shown in Figure 32a. On the other hand, burst testing at room temperature and up to $400{ }^{\circ} \mathrm{C}$ did not produce any rupture or any dimensional change of the cladding tubes. However, joint samples at higher temperatures did fail at the weld joint interface. A view of a failed burst specimen is shown in Figure 32b. Table 10 summarizes the burst results including relevant observations.

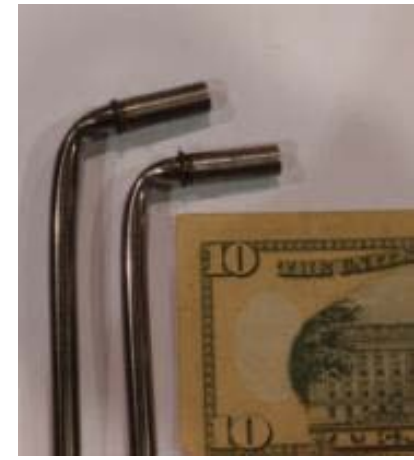

(a)

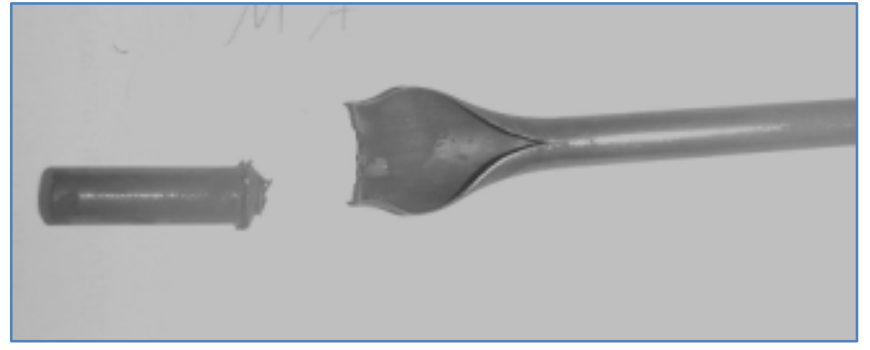

(b)

Figure 32. (a) Two bend tested MA957-HT9 PRW joints, (b) A failed burst test specimen at $575^{\circ} \mathrm{C}$ and a pressure of $13,000 \mathrm{psi}$. 
Table 10. Summary of the burst data obtained for the MA957-HT9 joints

\begin{tabular}{cccccc}
\hline Test \# & $\begin{array}{c}\text { Temperature } \\
\left({ }^{\circ} \mathrm{C}\right)\end{array}$ & $\begin{array}{c}\text { Pressure } \\
(\mathrm{psi})\end{array}$ & $\begin{array}{c}\text { Max. Uniform D } \\
\text { (in.) }\end{array}$ & $\begin{array}{c}\text { Max. } \\
\text { Diameter } \\
\text { (in.) }\end{array}$ & Observations \\
\hline 1 & 27 & 11,000 & 0.27 & 0.27 & No change \\
2 & 400 & 11,000 & 0.27 & 0.27 & No change \\
3 & 390 & 11,500 & 0.27 & 0.27 & No change \\
4 & 390 & 14,500 & 0.27 & 0.27 & $\begin{array}{c}\text { Held for 4977 min } \\
\text { Weld failed, held for } 9\end{array}$ \\
5 & 575 & 13,000 & 0.271 & 0.651 & min \\
6 & 650 & 8,000 & 0.299 & 0.703 & Weld failed, held for 1 \\
min
\end{tabular}

\section{EBSD and Microhardness Studies of MA957-HT9 Joints}

The cross-section of the MA957-HT9 PRW joint is shown in Fig. 33a. The resulting hardness data in Fig. 33b show that the bulk MA957 cladding tube and the bulk HT-9 end plug have a hardness of $370 \mathrm{HV}$ and $230 \mathrm{HV}$, respectively. The hardness of the bulk HT-9 correlates well to literature and the observed hardness in the bulk HT-9 in the spot welded sample (previously described). However, the hardened HT-9 region has an average hardness of approximately $490 \mathrm{HV}$, which is much less than what was observed in the HAZ of the HT-9 in the spot welded HT-9 to MA754 plate (630 HV).

The EBSD characterization was performed at the Center for Advanced Energy Studies (CAES) using a JEOL JSM-6610LV and associated EBSD hardware and software. The EBSD data collection was accomplished using an accelerating voltage of $20 \mathrm{kV}$ and a step size of $0.25 \mu \mathrm{m}$. The resulting EBSD analysis is shown in Fig. 34(a-d). The multiple EBSD scans show the microstructural evolution of both materials through each of their respective HAZ and through the weld interface very well. Notice that the step size of the EBSD scans was extremely small $(0.25 \mu \mathrm{m})$. This was to ensure that the extremely small grains of the HT-9 end plug be indexed with a high confidence. However, it is surprising to see that the bulk MA957 also required such a small step size due to its small microstructure. The weld interface is shown in the center of Figur 34c as a diagonal down-right change in grains. As seen in Fig. 34a, the bulk MA957 is highly textured and the grains are elongated along the length of the cladding tube. However, as the HAZ is reached (Figure 34a and b), the texture seems to shift to realign the $<101>$ planes and the long axes of the elongated grains rotates by approximately 90 degrees. The HAZ in the MA957 and HT-9 measures approximately $285 \mu \mathrm{m}$ and $340 \mu \mathrm{m}$ in length from the weld interface, respectively. 


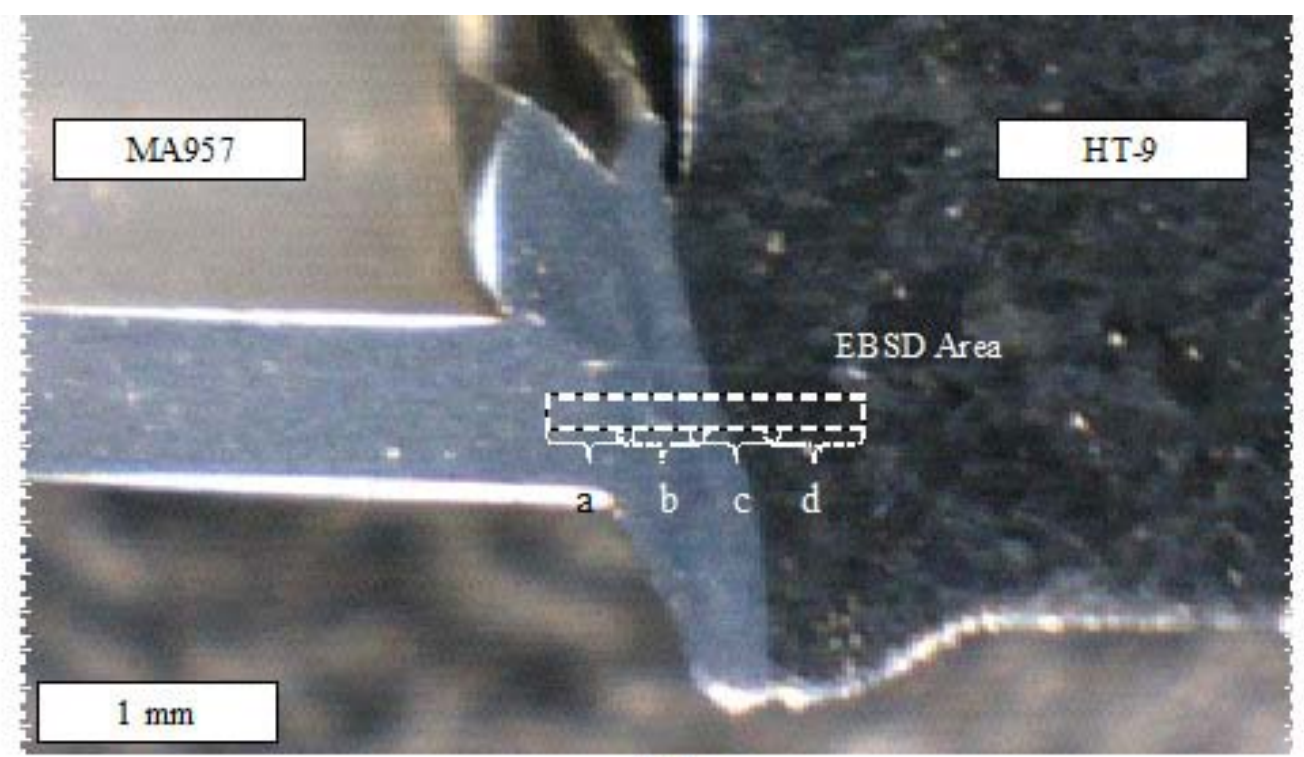

(a)

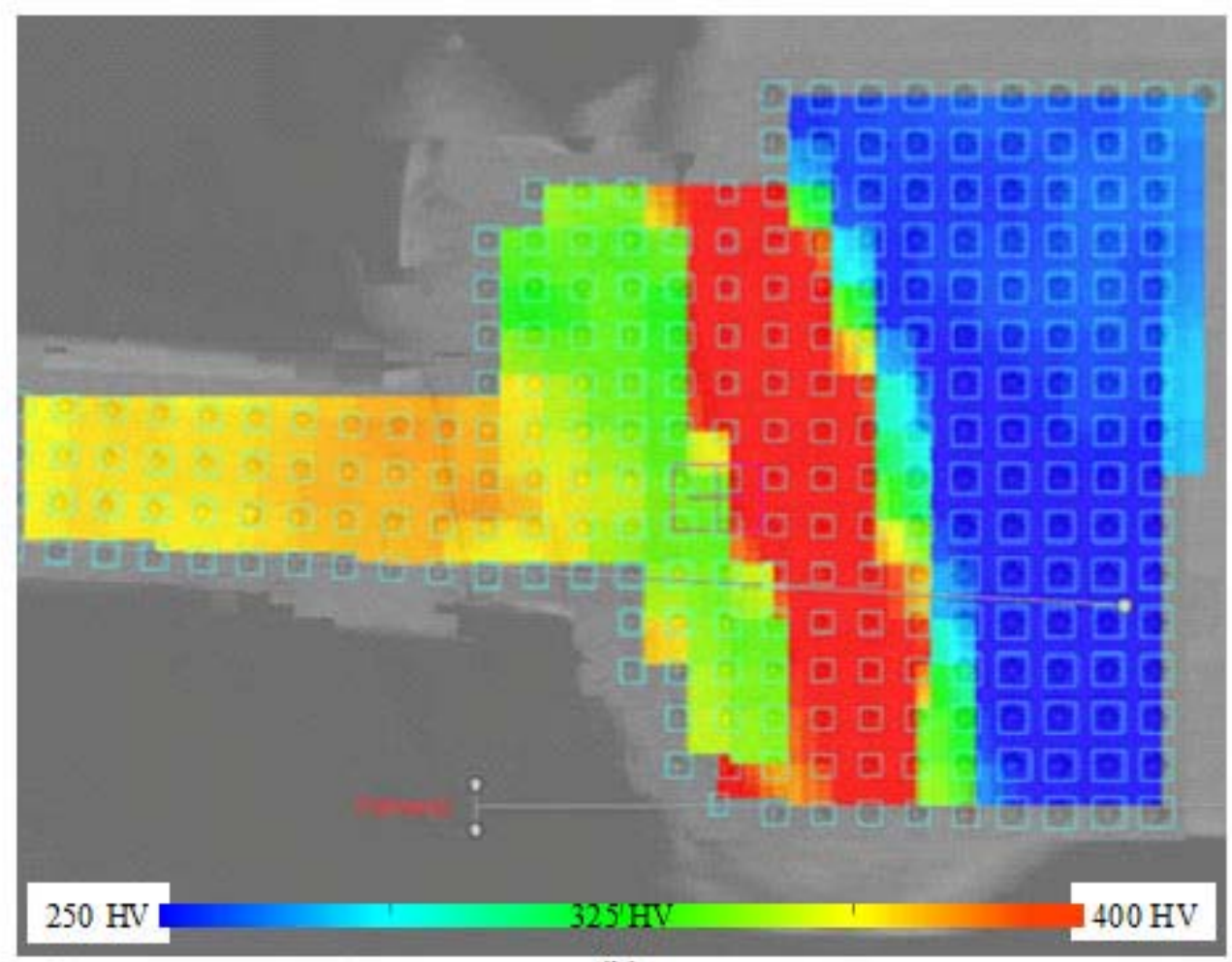

(b)

Figure 33. a) Optical microscopy image of the cross-section of the PRW joint between MA957 cladding tube and an HT-9 end plug showing a distinct transition region at the joint interface. Included on the image are the areas where EBSD was performed. b) Microhardness data superimposed on an optical microscopy image. 


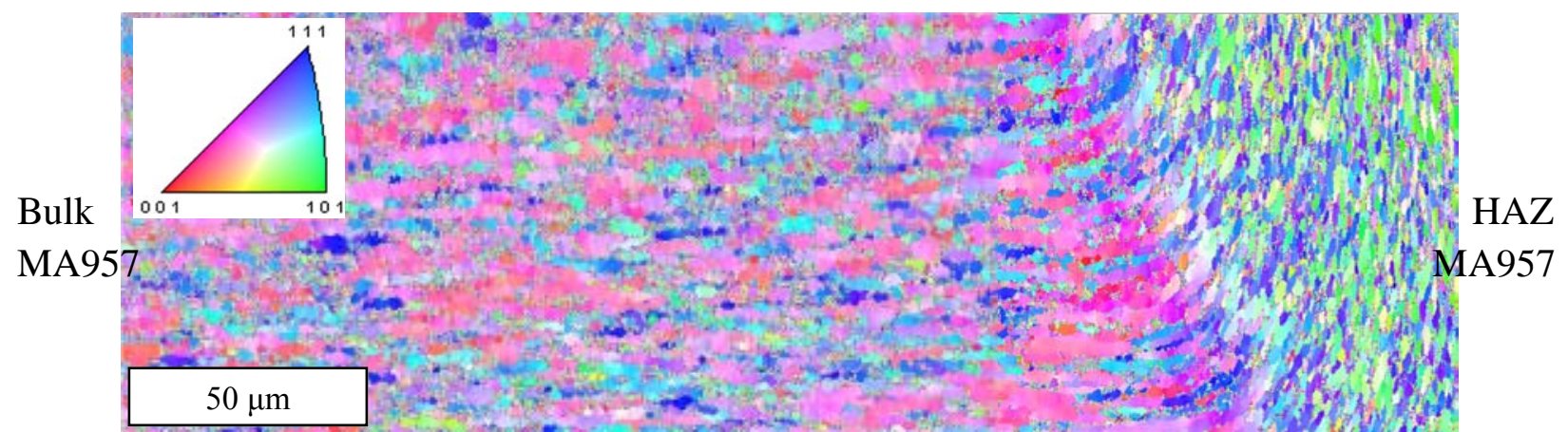

(a)

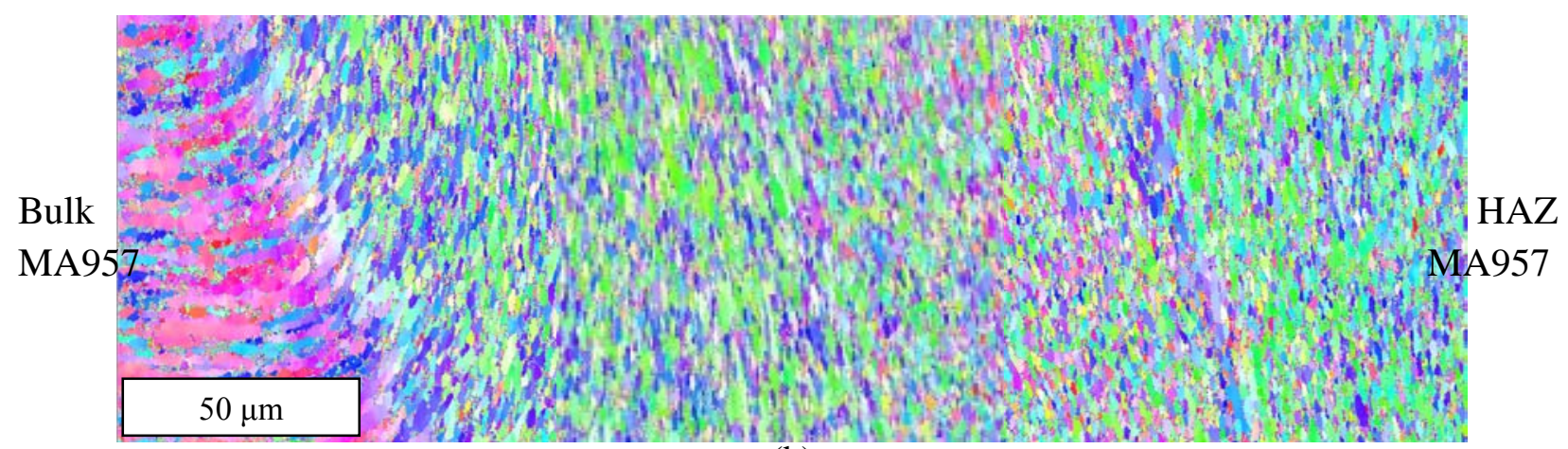

(b)

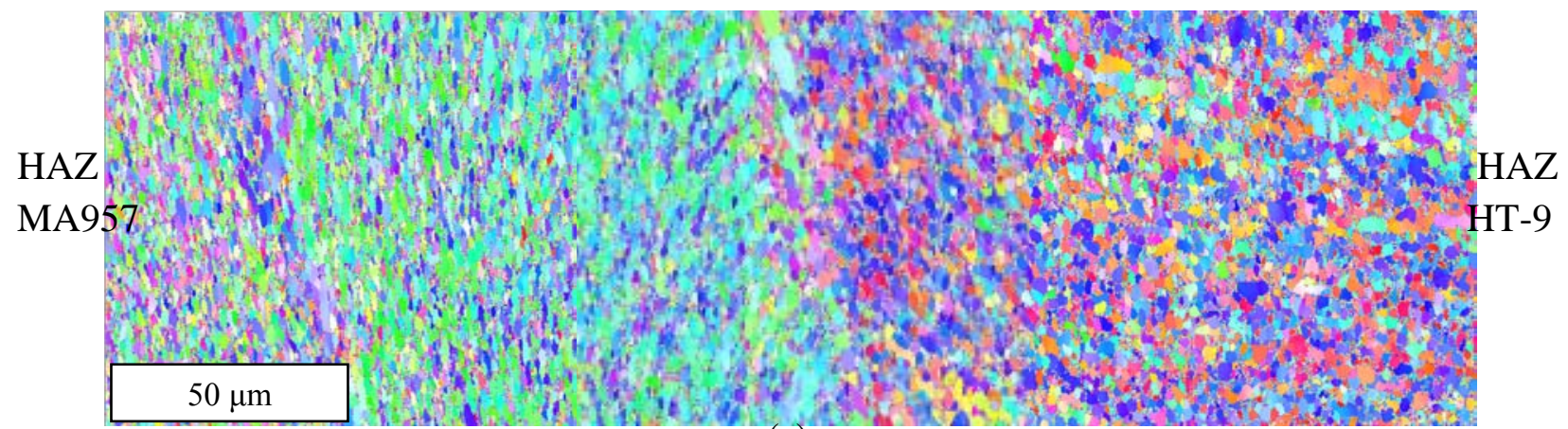

(c)

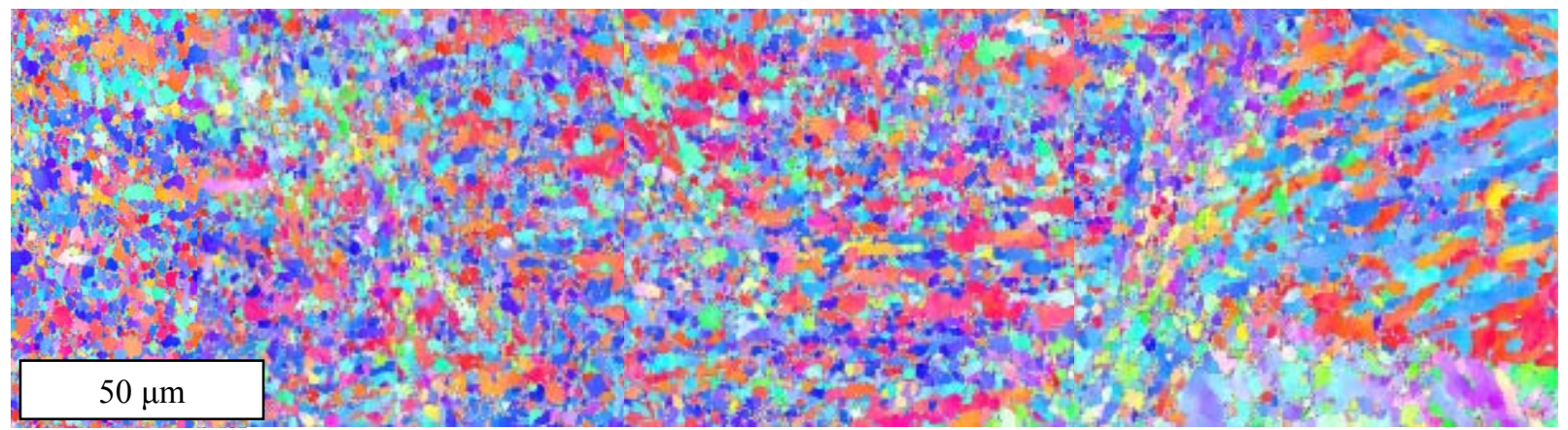

(d)

Figure 34. Resulting EBSD images from the MA957 cladding tube PRW to an HT-9 end plug. The EBSD results are from the MA957 cladding tube through the weld interface into the HT-9 end plug, from a-d and as shown in Fig. 33a. 


\section{PRW of MA754 and HT-9}

Several PRW joints between MA754 and HT9 joints (21 in total) were created. They appeared as shown in Figures 35a and 35b. Seven of the best samples were selected for further mechanical evaluation. Each of the seven samples were machined into compact tension specimens (CTS) using a wire electrical discharge machining (EDM) method with a $10 \mu \mathrm{m}$ wire as shown in Figure 36a. This geometry was chosen in order to evaluate the crack propagation behavior using the linear elastic fracture mechanics (LEFM) principles. Ideally, the machined crack tip would be at the center of the weld interface to allow the crack to initiate at the weld interface. However, due to the non-linear nature of the weld interface, aligning the machine-cut to the weld interface proved difficult. Figure 36b shows a corresponding conventional SEM image of the polished cross-section of the joint containing the crack tip.

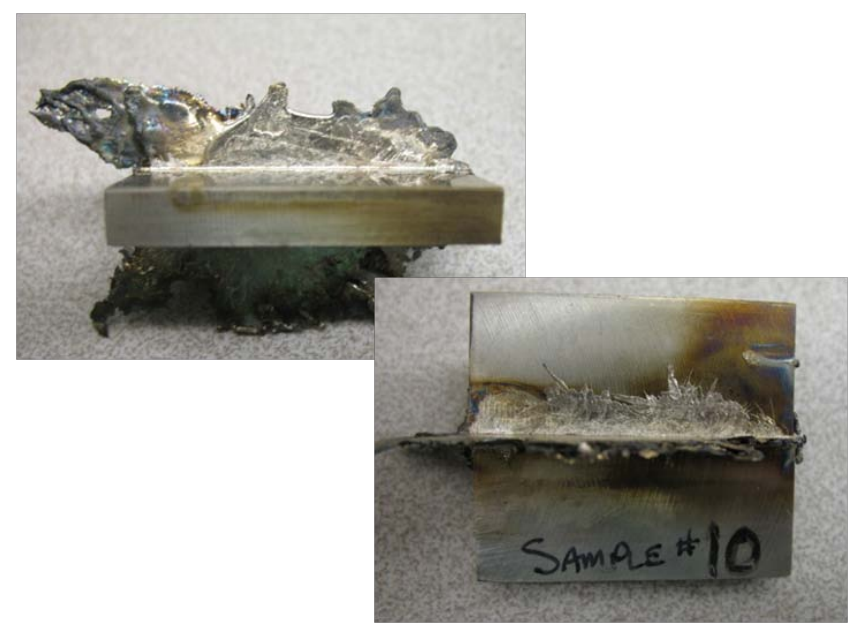

(a)

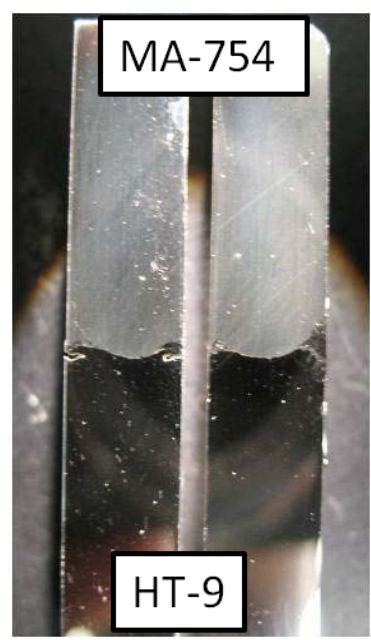

(b)

Figure 35. Macro-images of HT-9 to MA-754 joints created by pressure assistance welding. a) Asreceived joint showing the "flash" material. b) The polished cross section of the samples showing the HT9 and the MA-754 sides of the joint and the profile of the weld.
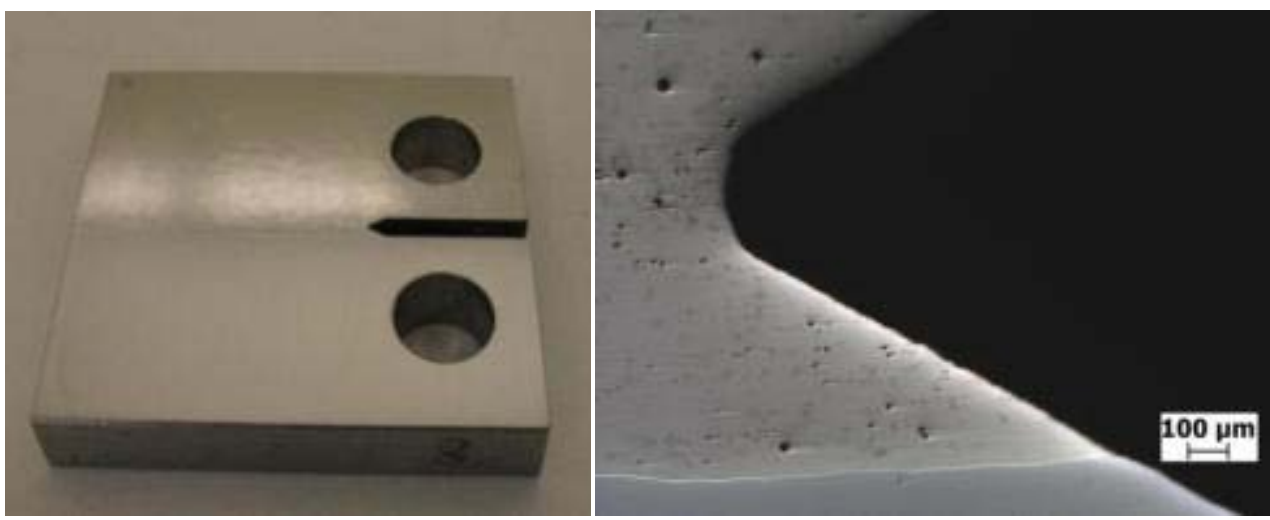

Figure 36. a) Image of a HT-9 to MA-754 PRW crack test specimen after polishing with a $6 \mu \mathrm{m}$ diamond slurry. The specimens were machined using a wire EDM technique to give precise crack tip geometry (shown by the SEM image of (b)) and a high tolerance mechanical test specimens. Notice the position of the joint relative to the crack tip. 
Prior to conducting the fatigue crack experiments, the microstructure of a joint sample was evaluated using the EBSD technique. The SEM and corresponding EBSD images are shown in Fig. 37. Given that the surface preparation is unique for each type of material and very important when using EBSD techniques, much time and effort were invested to provide sufficient relief for each of the two material surfaces without using a chemical etch (due to the adverse effects of the etch in the void space and the crack tip). The sample was first polished to 1200 grit using polishing cloths and diamond paste prior to being placed on a vibratory polisher in a colloidal silica slurry for 18 hours. Fig. 37a shows a low magnification SEM image of the crack tip of the CTS. A nickel phase was chosen for indexing the corresponding EBSD image (Fig. 37b). It should be noted that the confidence levels near the crack tip are relatively high but reduces as the distance from the crack tip increases. Also, not all of the specimen could be indexed due to the fact that iron phases were not indexed. Details of the fatigue crack experiments and further results will be published elsewhere. While more crack growth tests are currently ongoing, the specimen imaged above failed after about 4000 cycles.

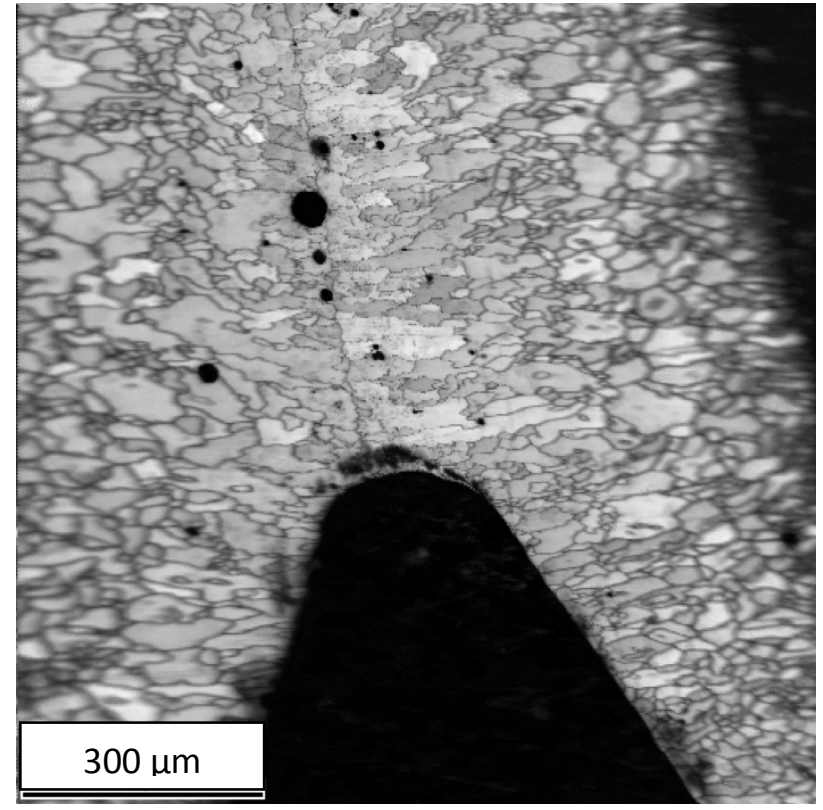

(a)

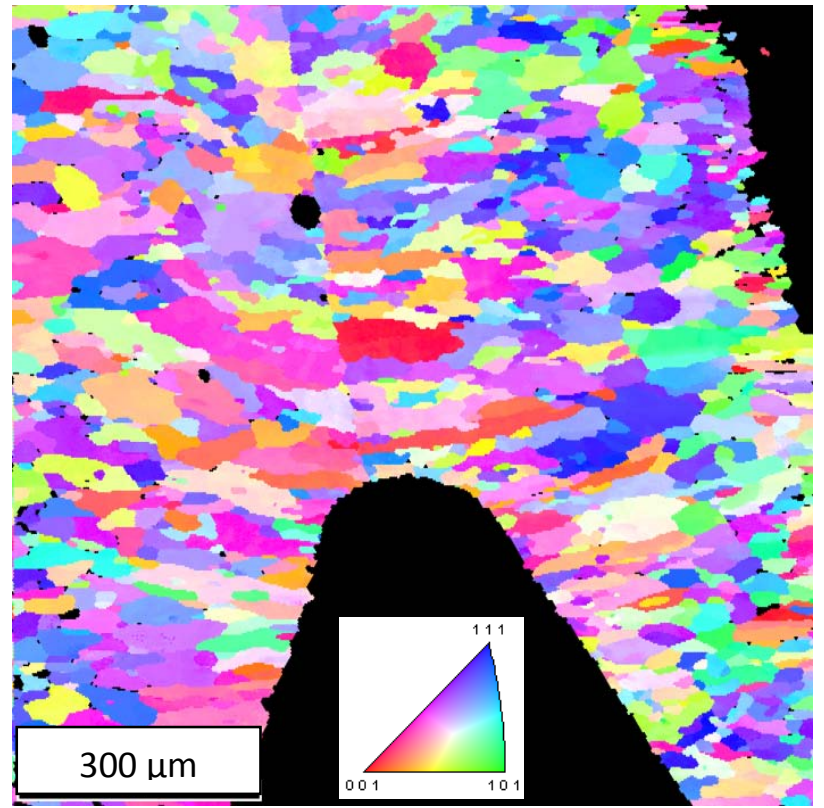

(b)

Figure 37. Microstructure of the HT-9 to MA-754 PRW joint. a) EBSD inverse pole figure map indexing the present nickel phase and b) the corresponding Kikuchi pattern quality map of the machined crack tip of a joint in a CTS.

\section{C1.3 Neutron Irradiation Studies}

As part of the ATR Scientific User Facility Program, shear punch and TEM samples from MA956 and MA754 alloys (both base and stir zone) have been irradiated in the Advanced Test Reactor (ATR) and are currently being deactivated. The details of the samples and irradiation conditions are summarized in Table 11. The thick TEM discs noted in the table will be used to carry out shear punch testing. It is expected that the ATR irradiated samples will be available during the early part of this year. Both types of samples will be studied for post-irradiation examination at the Materials and Fuels Complex (MFC), Idaho 
National Laboratory. Due to some disruption at the MFC, the schedule of the PIE has been delayed. Some samples have also been included in the PULSTAR reactor.

Table 11. A summary of irradiation conditions and sample details

\begin{tabular}{|c|c|c|c|c|}
\hline Material & $\begin{array}{c}\text { Sample Type and } \\
\text { Number }\end{array}$ & $\begin{array}{c}\text { Total Sample } \\
\text { Mass, gm }\end{array}$ & $\begin{array}{c}\text { ATR } \\
\text { Insertion }\end{array}$ & $\begin{array}{c}\text { Target } \\
\text { Dose }\end{array}$ \\
\hline \multirow{2}{*}{ MA956 } & $\begin{array}{c}\text { TEM Discs (8) } \\
\text { Thick TEM Discs ( 10) }\end{array}$ & $\begin{array}{c}0.05 \\
0.14\end{array}$ & $144 \mathrm{~A}, 2009$ & $1 \mathrm{dpa}$ \\
\hline \multirow{2}{*}{ MA956 } & TEM Discs (8) & 0.05 & $144 \mathrm{~A}, 2009$ & $2 \mathrm{dpa}$ \\
& Thick TEM Discs ( 10) & 0.14 & $144 \mathrm{~A}, 2009$ & $1 \mathrm{dpa}$ \\
\hline \multirow{2}{*}{ MA754 } & TEM Discs (8) & 0.06 & $144 \mathrm{~A}, 2009$ & $2 \mathrm{dpa}$ \\
\hline \multirow{2}{*}{ MA754 } & Thick TEM Discs ( 10) & 0.16 & 0.06 & \\
& Thick TEM Discs ( 10) & 0.16 & & \\
\hline
\end{tabular}

\section{PUBLICATIONS/PRESENTATIONS}

\section{D1. Thesis}

Kalyan Chitrada, "Thermal Stability Studies in Friction Stir Welded MA956 and MA754 Alloys,” MS Thesis, University of Idaho, August 11, 2010.

\section{D2. Peer-Reviewed Proceeding Paper}

N. Jerred*, L. Zirker, B. Jaques, T. Bradshaw, J. Carrillo, E. Young, I. Charit, J. Cole, M. Frary, D.P. Butt, M. Meyer, and K.L. Murty, "Pressure Resistance Welding of High Temperature Metallic Materials," Joining of Advanced and Specialty Materials XII Symposium, MS\&T 2010 Conference, Houston, Oct. 17-21, 2010.

\section{D3. Conference Presentations}

1. E. Young, J. Carillo, B. Jaques, J. Burns, L. Zirker, I. Charit, D.P. Butt, M. Frary, "Mechanical Properties and Microstructural Evolution of ODS Alloys Joined by Solid State Welding," Materials for the Nuclear Renaissance II, TMS Annual Meeting, Feb. 28 - Mar. 3, 2011, San Diego, USA.

2. N. Jerred, L. Zirker, I. Charit, J. Cole, B. Jaques, T. Bradshaw, J. Carillo, E. Young, M. Frary, D.P. Butt, M. Meyer, and K.L. Murty, "Pressure Resistance Welding for Advanced Reactor Applications,” Materials for the Nuclear Renaissance II, TMS Annual Meeting, Feb. 28 - Mar. 3, 2011, San Diego, USA.

3. R. Prabhakaran, J. Wang, I. Charit, J. Cole, K.L. Murty, and R.S. Mishra, "Microstructure and Mechanical Properties of Irradiated Friction Stir Welded ODS Alloys," Materials for the Nuclear Renaissance II, TMS Annual Meeting, Feb. 28 Mar. 3, 2011, San Diego, USA. 
4. R. Prabhakaran*, J. Wang, W. Yuan, K. Chitrada*, J. Cole, I. Charit, and R.S. Mishra, "Friction Stir Welding of Oxide Dispersion Strengthened Alloys," ANS Annual Meeting, San Diego, CA, June 13-17, 2010 (poster).

5. R. Prabhakaran*, J. Wang, K. Chitrada*, W. Yuan, I. Charit, J. Cole, R. Mishra, "Microstructural and Mechanical Characteristics of Friction Stir Welded ODS Alloys," Mechanical Performance for Current and Next Generation Nuclear Reactors, TMS Annual Meeting, Seattle, Feb. 14-18, 2010.

6. K. Chitrada*, R. Prabhakaran*, J. Wang, L. Zirker, M. Meyer, J. Cole, K.L. Murty, R. Mishra, D. Butt, M. Frary, and I. Charit, "Weldability Characteristics of Oxide Dispersion Strengthened Alloys: An Overview,” Nuclear Energy: Processes and Policies, TMS Annual Meeting, Seattle, Feb. 14-18, 2010.

7. J. Wang, W. Yuan, R. Mishra and I. Charit, "Friction Stir Welding of DispersionStrengthened Alloy MA754,” Nuclear Energy Processes and Policies, TMS Annual Meeting, Seattle, Feb. 14-18, 2010.

8. I. Charit, "Solid State Welding Characteristics of Oxide Dispersion Strengthened Alloys," School of Mechanical and Materials Engineering, Washington State University, Dec. 3, 2009 (invited).

9. R. Prabhakaran*, J. Wang, W. Yuan, K. Chitrada*, I. Charit, and R. S. Mishra, "Microstructure and Mechanical Properties of Friction Stir Welded MA956 and MA754 Alloys,” Materials Solutions for the Nuclear Renaissance, Materials Science and Technology 2009, Pittsburgh, Oct. 25-29, 2009.

10. I. Charit, R.S. Mishra, D. Butt, K.L. Murty, J.I. Cole, M. Meyer, and L. Zirker, "Solid State Joining of Oxide Dispersion Strengthened Alloys,” Joining of Advanced and Specialty Materials 2009 (JASM XI), Materials Science and Technology 2009, Pittsburgh, Oct. 25-29, 2009.

11. R. Prabhakaran*, W. Yuan, J.I. Cole, R.S. Mishra, and I. Charit, "Microstructure and Mechanical Properties of Friction Stir Welded MA956,” Friction Stir Welding and Processing Symposium, TMS Annual Meeting, San Francisco, Feb. 15-19, 2009.

12. I. Charit, "Weldability in ODS alloys for AFCI/GNEP," Transmutation Fuel Campaign Meeting, Salt Lake City, UT, Oct. 27-28, 2008 (invited).

D4. Two journal papers are being prepared for submission to journals. Two more will be published

\section{E. STUDENTS INVOLVED}

We recruited a few students to work on the concluded project (see Table 12). Involvement of students is critical as we develop the educational infrastructure needed for trained scientific workforce during the course of the project. Students are also interfacing with INL researchers gaining unique experience and perspective.

Table 12. A list of students involved in the project at different universities

\begin{tabular}{|l|c|c|}
\hline Institution & Student's name & Degree / Discipline \\
\hline University of Idaho & $\begin{array}{c}\text { Ramprashad Prabhakaran } \\
\text { (expected summer 2011) } \\
\text { Kalyan Chitrada }\end{array}$ & $\begin{array}{c}\text { Ph.D. / MSE } \\
\text { M.S. / MSE }\end{array}$ \\
\hline
\end{tabular}




\begin{tabular}{|l|c|c|}
\hline & (gradauted with MS in summer 2010) & M.S. / NE \\
\hline Boise State University & Nathan Jerred & B.S. / MSE \\
& Chris Stifter & \\
\hline $\begin{array}{l}\text { North Carolina State } \\
\text { University }\end{array}$ & Troung & M.S. / NE \\
\hline Missourillo S\&T & Jiye Wang (ongoing) & Ph.D. / MSE \\
\hline
\end{tabular}

Note. MSE is 'Materials Science and Engineering' and NE is 'Nuclear Engineering.'

\section{F. CONCLUDING REMARKS}

The project carried out highlighted several new findings. It was demonstrated that a number of ODS alloys and ODS to dissimilar alloys can be successfully welded using solid state joining techniques. Detailed microstructural characterization and mechanical properties were evaluated. Both FSW and PRW are worth solid state joining techniques to be considered. The irradiation tests will be done in due course and with the results becoming available, the suitability of the ODS alloys for fuel cladding materials will be more clear. All results could not be included here, but will be communicated through journal publications in due course.

\section{G. REFERENCES}

Benjamin, J.S., “Dispersion Strengthened Superalloys by Mechanical Alloying,” Met. Trans., 1 (1970) 2943.

Bottcher, J., Ukai, S., and Inoue, M., “ODS Steel Clad MOX Fuel-Pin Fabrication Peformance in EBR-II,” Nuc. Tech., 138 (2002) 238.

Busby, J.T., “Advanced Structural Materials Program,” ABR Campaign, Global Nuclear Energy Partnership, June 2007.

Cahalan, J., "Sodium Fast Reactor / Advanced Burner Reactor,” Advanced Reactor, Fuel Cycle, and Energy Products Workshop for Universities, Hilton Hotel, Gaithersburg, MD, Mar. 2007.

Feng, Zhili, and Ren, Weijun, "Initial investigation on joining ODS alloy using friction stir welding for Gen IV nuclear reactor heat exchanger applications," Proceedings of ASME Pressure Vessels and Piping Conference - Materials and Fabrication, 2008, 431-438.

Hoelzer, D.T., Bentley, J., Sokolov, M.A., Miller, M.K., Odette, G.R., and Alinger, M.J., "Influence of Particle Dispersions on the High Temperature Strength of Ferritic Alloys," J. Nuclear Materials, (2007) in press.

Kim, I., Choi, B.Y., Kang, C.Y., Okuda, T., Maziasz, P., and Miyahara, K., "Effect of Ti and W on the Mechanical Properties of 12\%Cr Base Mechanical-Alloyed Nano-Sized ODS Ferritic Alloys,” ISIJ International, 43 (2003) 1640.

Kimura, A., Cho, H., Toda, N., Kasada, R., Kishimoto, H., Iwata, N., Ukai, S., Ohtsuka, S., Fujiwara, M., "Fuel Cladding Materials R\&D for High Burn-Up Operation of Advanced Nuclear Energy System,” Proceedings of ICAPP’06, June 4-8, 2006, Paper 6456, 2229. 
Klueh, R.L., Shingledecker, J.P., Swindeman, R.W., and Hoelzer, D.T., “Oxide DispersionStrengthened Steels: A Comparison of Some Commercial and experimental Alloys,” J. Nuc. Mater., 341 (2005) 103.

Legendre, F., Poissonnet, S., Bonnaillie, P., Boulanger, L., and Forest, L., "Some Microstructural Characteristics in a Friction Stir Welded Oxide Dispersion Strengthened Ferritic Steel Alloy," Journal of Nuclear Materials, 386-388 (2009) 537-539.

Miller, M.K., Kenik, E.A., Heatherly, L., Hoelzer, D.T., Maziasz, P.J., “Atom Probe Tomography of Nanoscale Particles in ODS Ferritic Alloys,” Materials Science and Engineering A, 353 (2003) 140.

Monnet, I., Dubuisson, P., Serruys, Y., Ruault, M.O., Kaitasov, O., and Jouffrey, B., "Microstructural Investigation of the Stability Under Irradiation of Oxide Dispersion Strengthened Ferritic Steels,” J. Nuclear Materials, 335 (2004) 311.

Seki, M., Hirako, K., Kono, S., Kihara, Y., Kaito, T., and Ukai, S., "Pressurized Resistance Welding Technology Development in 9Cr-ODS Martensitic Steels,” J. Nuc. Mater., 329-333 (2004) 1534.

Thomas, W.M., Nicholas, E.D., Needham, J.C., Murch M.G., Templesmith, P., and Dawes, C.J., Friction Stir Butt Welding, U.S. Patent No. 5460317, 1995.

Zirker, L.R., Bottcher, J.H., Shikakura, S., Tsai, C.L., and Hamilton, M.L., "Fabrication of Oxide Dispersion Strengthened Ferritic Clad Fuel Pins," International Conf. on Fast Reactors and Related Fuel Cycles, Oct. 28-31, 1991, Kyoto, Japan. 